\title{
Development and Testing of a Sorbent-Based Atmosphere Revitalization System 2010/2011
}

\author{
Lee A. Miller ${ }^{1}$ \\ ECLS Technologies, LLC., Huntsville, AL, 35802 \\ and \\ James C. Knox ${ }^{2}$ \\ NASA, Marshall Space Flight Center, 35812
}

\begin{abstract}
Spacecraft being developed for future exploration missions incorporate Environmental Control and Life Support Systems (ECLSS) that limit weight, power, and volume thus requiring systems with higher levels of efficiency while maintaining high dependability and robustness. For air revitalization, an approach that meets those goals utilizes a regenerative Vacuum-Swing Adsorption (VSA) system that removes $100 \%$ of the $\mathrm{CO}_{2}$ from the cabin atmosphere as well as $100 \%$ of the water. A Sorbent Based Atmosphere Revitalization (SBAR) system is a VSA system that utilizes standard commercial adsorbents that have been proven effective and safe in spacecraft including Skylab and the International Space Station. The SBAR system is the subject of a development, test, and evaluation program that is being conducted at NASA's Marshall Space Flight Center. While previous testing had validated that the technology is a viable option, potential improvements to system design and operation were identified. Modifications of the full-scale SBAR test articles and adsorption cycles have been implemented and have shown significant performance gains resulting in a decrease in the consumables required for a mission as well as improved mission safety. Previous testing had utilized single bed test articles, during this period the test facility was enhanced to allow testing on the full 2-bed SBAR system. The test facility simulates a spacecraft ECLSS and allows testing of the SBAR system over the full range of operational conditions using mission simulations that assess the real-time performance of the SBAR system during scenarios that include the metabolic transients associated with extravehicular activity. Although future manned missions are currently being redefined, the atmosphere revitalization requirements for the spacecraft are expected to be quite similar to the Orion and the Altair vehicles and the SBAR test program addressed validation to the defined mission requirements as well as operation in other potential vehicle architectures. The development program, including test articles, the test facility, and tests and results through early 2011 is discussed.
\end{abstract}

\section{Introduction}

A development, test, and evaluation program is being conducted at NASA, Marshall Space Flight Center to assess the performance of the Sorbent-Based Atmosphere Revitalization (SBAR) system for meeting $\mathrm{H}_{2} \mathrm{O}$ and $\mathrm{CO}_{2}$ removal requirements for manned spacecraft. The SBAR system incorporates materials and technologies that have operated successfully in previous programs and provides a low risk alternative for cabin atmosphere revitalization. The overall purpose of this program is to identify and implement improvements to the SBAR design and to then evaluate the SBAR technology for use in spacecraft Environmental Control and Life Support Systems (ECLSS). The early focus of this project was in direct application of the technology for the requirements of the Constellation Program. The SBAR design enhanced and evaluated during this program is based on previous development and characterization efforts which validated the SBAR technology as a viable alternative for use in the Orion Crew

\footnotetext{
${ }^{1}$ Senior Engineer, 8811 Valley View Dr., Huntsville AL, Senior Member.

2 Aerospace Engineer, ECLSS Development Branch, MS ED62, MSFC, Huntsville AL, non-member.
}

1

American Institute of Aeronautics and Astronautics 
Exploration Vehicle (CEV) ${ }^{1,2}$ Subsequent testing has addressed the requirements specific to the Altair Lunar Lander such as missions that included extensive periods of Extra-Vehicular Activity (EVA).

The tests and analyses performed verified that an SBAR System is a viable and safe system for $\mathrm{CO}_{2}$ and $\mathrm{H}_{2} \mathrm{O}$ removal within the Altair vehicle as defined by the Constellation Program. In addition, implementation of configuration changes to the design has improved performance and operational margins thereby enhancing overall vehicle safety. The technology and the test data obtained are also applicable for any vehicle where mission requirements and vehicle architecture justify an open-loop regenerative Atmosphere Revitalization System (ARS). As the development program progressed, vehicle architectures and missions outside of those defined by the Constellation Program were identified. Tests of the SBAR system with defined conditions based on potential vehicle architectures and mission scenarios were also performed to evaluate the technology's potential in these newly identified applications.

The SBAR system utilizes a regenerable zeolite-based Vacuum Swing Adsorption (VSA) process which has been successfully used in manned spacecraft for $\mathrm{CO}_{2}$ removal but has not previously been used as the sole system designated for removing and controlling humidity. Metabolic water from respiration and evaporated sweat has traditionally been removed by a condensing heat exchanger (CHX). Adsorption-based water removal systems eliminate the need for a CHX (though a sensible heat exchanger is still required), gas/liquid separators and the CHX requirement for a low temperature coolant loop; however, it places additional challenges on the VSA system. ${ }^{3}$

\section{SBAR Technology}

An air revitalization system is an integral part of any spacecraft ECLSS and must reliably perform over a wide range of cabin conditions. Figure 1 shows a simplified ARS loop which illustrates the two primary modes of operation; 1) the normal mode in which cabin air is pulled through the SBAR System and then returned to the cabin volume, and 2) the suit loop mode in which the conditioned air flows directly to the crewmember's suits. In the suit loop mode the SBAR has to operate at pressures as low as 4.3 psia (225 Torr) and the entire volume in the loop is quite small. For both modes, all water and $\mathrm{CO}_{2}$ generated by crew activity must be removed by the SBAR thereby alleviating the need for a condensing heat exchanger.

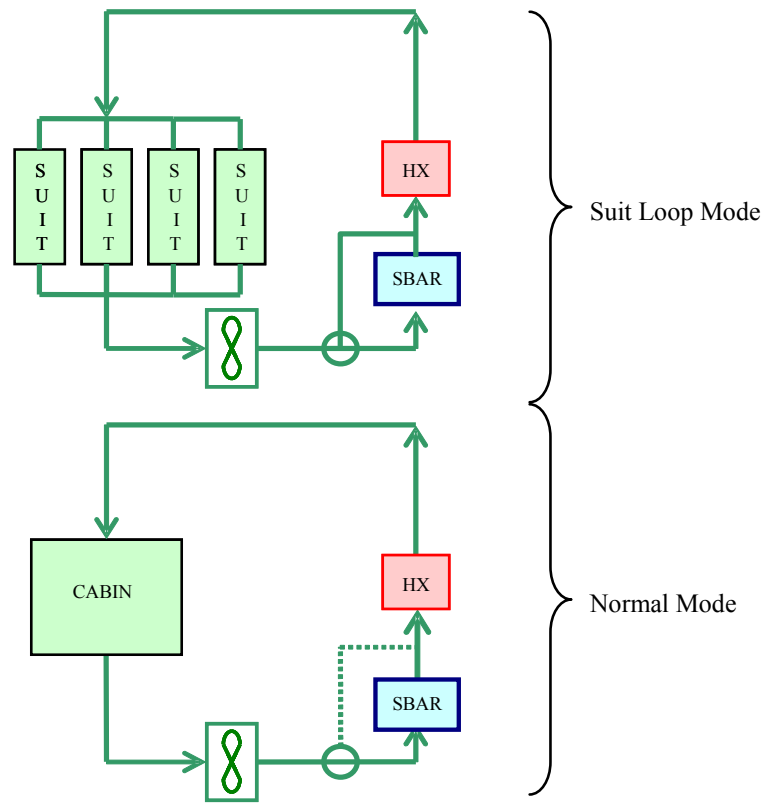

Figure 1 Simplified ARS Schematic

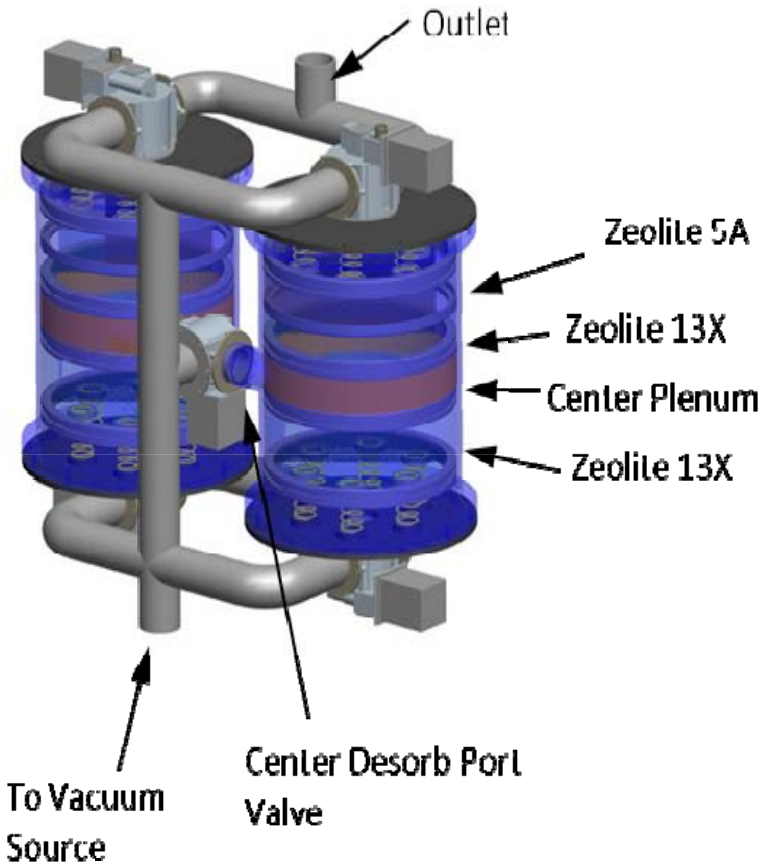

Figure 2 SBAR Bed Layer Configuration

The SBAR system utilizes zeolite molecular sieve types $13 \mathrm{X}$ and 5A packed in layers in bed assemblies. Each SBAR unit is comprised of a 2-bed assembly. Figure 2 shows the layout and depicts the layering of the zeolite material within the beds. The beds have a center plenum and are packed from both ends with spring loaded baffle plates maintaining compression on the packed material. For the tested SBAR system, each bed contained a total of 
6.6 liters of zeolite material. By definition, physical adsorbents do not change upon adsorbing a molecule from a fluid stream, either geometrically (such as swelling) or chemically (as in amine reactors). Molecular sieves are a special class of adsorbent due to their crystalline structure which provides a precise pore size and negative polar moment. Various chemical compositions and crystal types are available which have pore sizes from $3-10$ angstroms. The polar surface of the pores strongly attracts both carbon dioxide and water, which are also polar, resulting in high sorbent capacities even at low concentrations. The system is regenerable and does not require consumables either for $\mathrm{CO}_{2}$ or humidity removal.
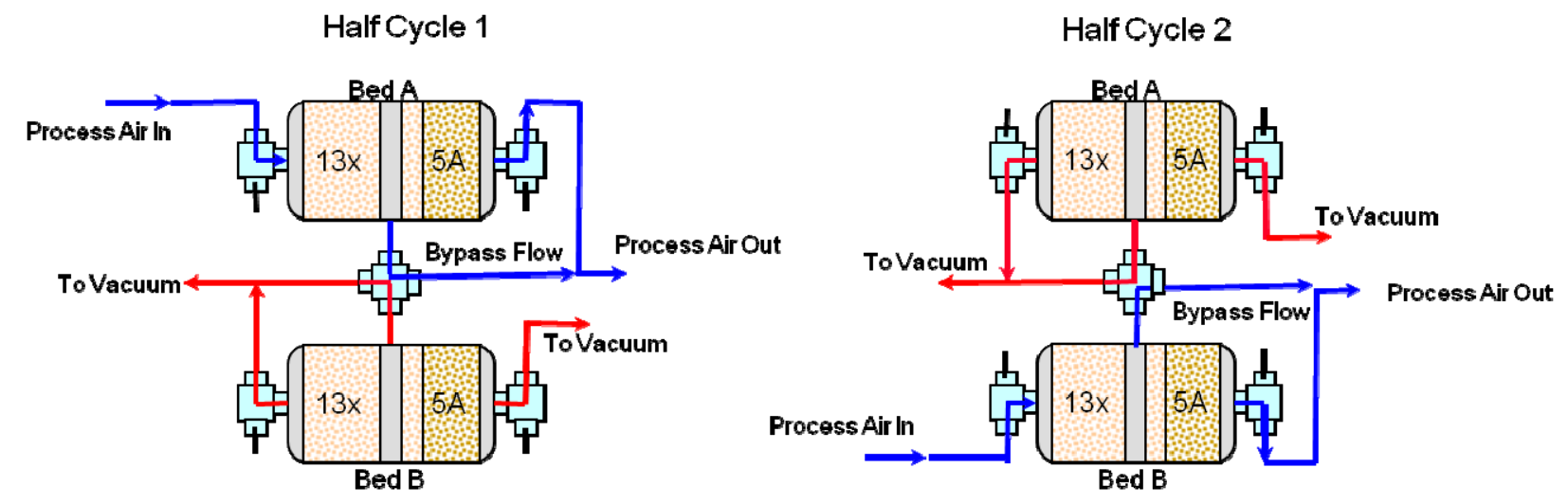

Air Save 1-2

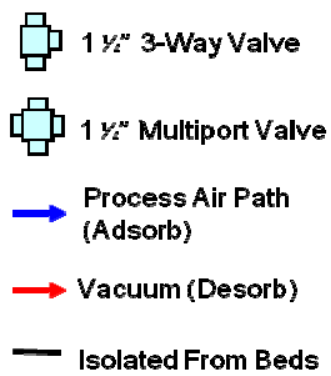

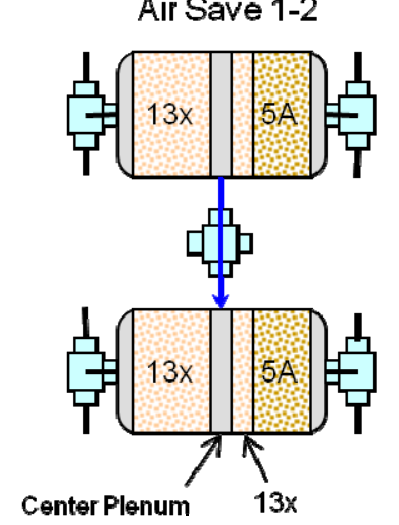

Figure 3 SBAR VSA Cycle Schematic Showing Bypass Flow

Air Save 2-1

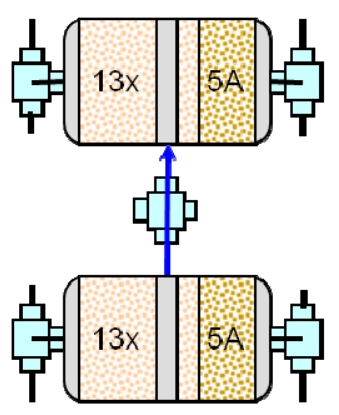

Figure 3 shows a schematic of SBAR system cyclic operation. The SBAR uses vacuum to desorb the previously adsorbed $\mathrm{CO}_{2}$ and $\mathrm{H}_{2} \mathrm{O}$. For the adsorb half-cycle, the $\mathrm{CO}_{2}$ and water vapor laden gas is drawn from the cabin/suit loop through the adsorbing bed. All of the flow passes through the first 13X layer of the bed which, during nominal flow conditions, removes nearly $99 \%$ of the water vapor. A controlled portion of the dehydrated flow is allowed to bypass downstream bed layers and is returned to the cabin. The remainder of the flow passes through an additional layer of $13 \mathrm{X}$ to remove any residual moisture and then through the $5 \mathrm{~A}$ material to remove the $\mathrm{CO}_{2}$. The $\mathrm{CO}_{2}$ removal efficiency is affected by residence time and the amount of $\mathrm{H}_{2} \mathrm{O}$ that had previously been absorbed by the material.

The second bed of the system is simultaneously placed under vacuum to allow the $\mathrm{CO}_{2}$ and $\mathrm{H}_{2} \mathrm{O}$ to be removed. The SBAR bed assembly has three locations for vacuum access, at the inlet, center, and outlet ports of the bed. The center port provides access to space vacuum for water desorption, increasing water removal performance, retarding propagation of water through the bed, and reducing the size and weight of the inlet vacuum line and valves. At the end of each half-cycle, both beds are temporarily isolated from the external interfaces and allowed to equalize with each other. This decreases the amount of ullage gas lost during half-cycle changes. The valves are sequenced during the desorb half-cycle so that the vacuum source is opened to the flow inlet end of the bed (13X side) first. The center port is then opened to the vacuum source and then finally the $5 \mathrm{~A}$ end of the bed is placed under vacuum. This 
sequence insures that the material with the greatest water loading is evacuated first and that the flow direction minimizes water propagation into the $5 \mathrm{~A}$ material.

A goal of the development effort has been to improve overall performance to the point that an SBAR system will maintain sufficient $\mathrm{CO}_{2}$ removal efficiency to complete the mission duration while operating only in the VSA mode. However, over the length of a mission, particularly one in which high metabolic loads are encountered, the water load on the $5 \mathrm{~A}$ material may eventually degrade $\mathrm{CO}_{2}$ removal performance below acceptable levels. To recover the performance a thermal regeneration would be required. For thermal regeneration the bed is opened to the vacuum of space and the zeolite material is heated, thereby removing virtually all the adsorbed water. After thermal regeneration an SBAR system fully recovers to the initial $\mathrm{CO}_{2}$ removal performance. While the bed is being heated it is unavailable for atmosphere revitalization. Regardless of metabolic load, it is expected that a spacecraft ARS would incorporate two independent SBAR systems to meet the goals of reliability and redundancy.

\section{SBAR Test Facility}

The Spacecraft ECLSS Simulator (SES) is the integrated hardware and software system designed to simulate the full range of cabin conditions anticipated throughout a defined mission scenario while capturing all required performance parameters. The SES controls the inlet conditions to the SBAR based on simulated cabin $\mathrm{CO}_{2}$ and humidity levels. The SES incorporates the capability to operate at sub-ambient absolute pressures and to control to dynamically changing real-time cabin $\mathrm{CO}_{2}$ and humidity levels. The capability to control bypass of the $\mathrm{CO}_{2}$ removing layers of the bed as a function of simulated cabin $\mathrm{CO}_{2}$ level to a setpoint is also incorporated into the SES design.

The SES utilizes the LabView ${ }^{\circledR}$ programming software for control system functions and the MSFC developed PACRATS (Payload And Components Real-time Automated Test System) software for data recording and display. Figure 4 shows a screenshot of the LabView ${ }^{\circledR}$ control panel. Commercially available components and parts were utilized to implement the SES. When needed, components were modified, either by the vendor or in-house, to meet unique operational requirements.

The SES:

- Controls, monitors, and records SBAR inlet conditions.

- Monitors and records SBAR outlet conditions.

- Calculates and records real-time performance parameters.

- Includes redundant measurements to allow in-situ instrumentation verification and real-time fault detection.

- Incorporates a model of the Cabin / Suit Loop configurations to allow ARS inlet conditions to be controlled as a function of cabin conditions.

- Controls the bypass valve to precise positions to allow control of $\mathrm{CO}_{2}$

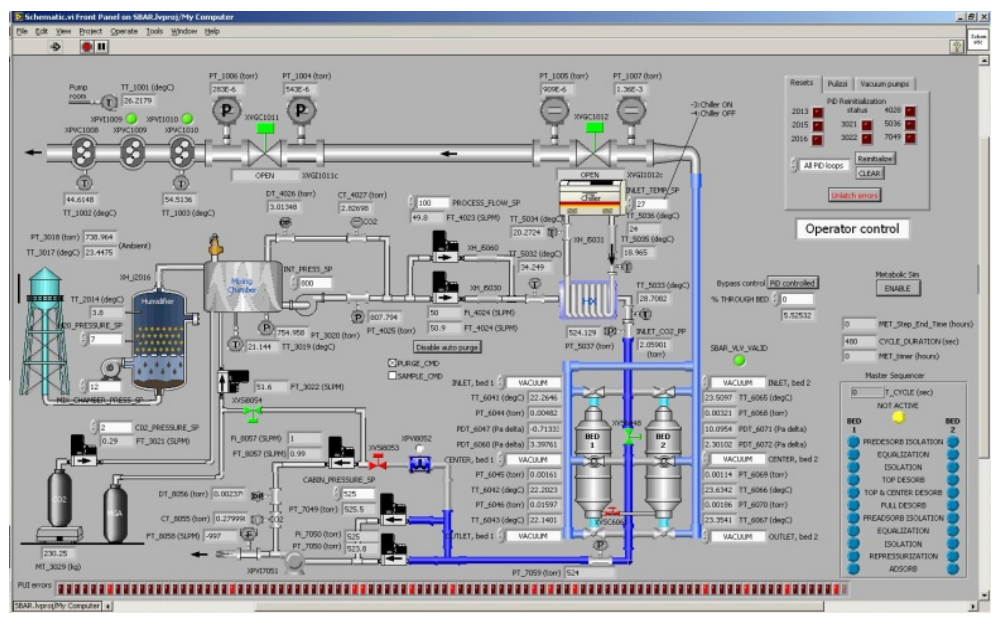

Figure 4 SES Control Panel Allows Manual Control As Well As Automatic Operation

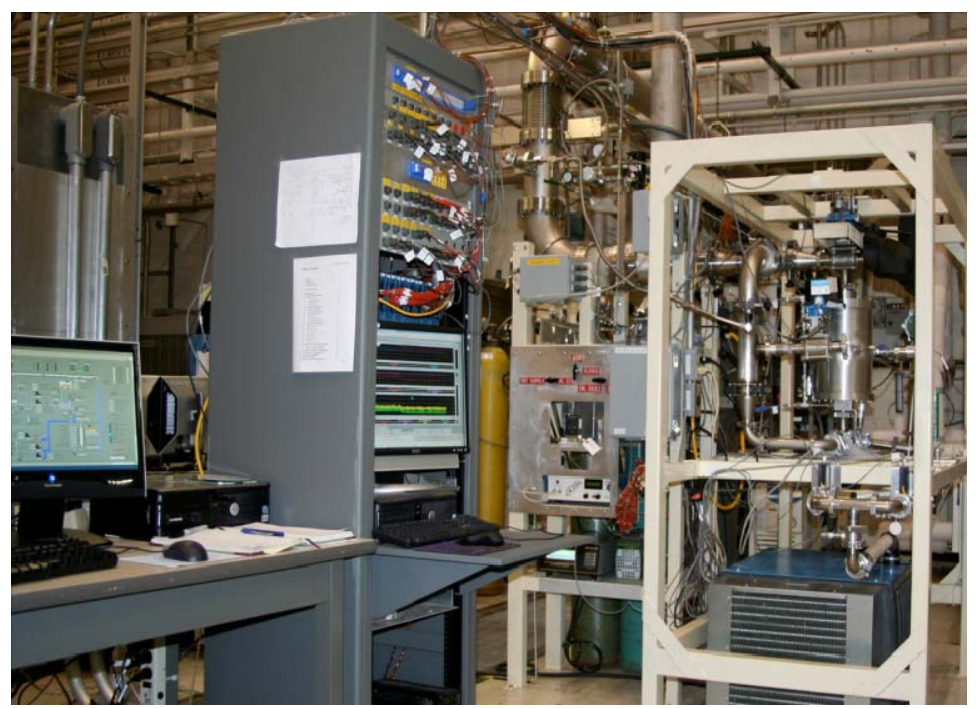

Figure 5 SBAR Test Facility is Designed for Ease of Reconfiguration and Expansion

American Institute of Aeronautics and Astronautics 
levels independent of water vapor removal requirements.

- Acquires sensor data and updates control loops at $5 \mathrm{~Hz}$ rate and records 106 channels of sensor data and 153 channels of calculated and status parameters at a $1 \mathrm{~Hz}$ rate.

The SES controls and monitors the SBAR inlet conditions to within the limits of:

- Temperature $5-35^{\circ} \mathrm{C} \pm 1{ }^{\circ} \mathrm{C}\left(41-95^{\circ} \mathrm{F}\right)$

- Pressure $200-875$ Torr $\pm 1 \%(4-16.9$ psia)

- $\mathrm{H}_{2} \mathrm{O}$ Partial Pressure $0.01-35$ Torr $\pm 1 \%\left(-63^{\circ} \mathrm{C}-31.5^{\circ} \mathrm{C}\right)\left(-81^{\circ} \mathrm{F}-88^{\circ} \mathrm{F}\right.$ dew point $)$

- $\mathrm{CO}_{2}$ Partial Pressure $0.5-10$ Torr $\pm 1 \%$

- ARS Flow $100-1500 \mathrm{SLPM} \pm 1 \%(3.5-53 \mathrm{SCFM})$

Control of the SBAR inlet humidity to low dew points $\left(<-60^{\circ} \mathrm{C}\right)$ is among the added capabilities recently incorporated into the SES. This allowed testing and evaluating the SBAR technology for $\mathrm{CO}_{2}$ removal only applications, such as would be the operational mode when integrated into a vehicle with a water recovering ECLSS architecture.

Figure 5 shows a photograph of the test facility which is located at NASA, Marshall Space Flight Center. The facility is modular and has been designed to allow reconfiguration to address changes in test parameters and mission objectives. Testing was primarily performed with the SES in a single bed configuration where operation of an SBAR system's second bed assembly was simulated. This minimized the time between test cases thereby allowing testing to proceed at a faster rate. The capability to test in the full 2-bed SBAR configuration has been incorporated and is being used to assess the impact of changes in valve sequencing and the bed pressure equalization process.

Figure 6 is a photograph of the SBAR system integrated with the SES. The test article is extensively instrumented to allow full characterization of system performance. Sensors integrated with the test article include vacuum/pressure transducers at the top (inlet), the center plenum, and the bottom (outlet) while thermocouples measure the

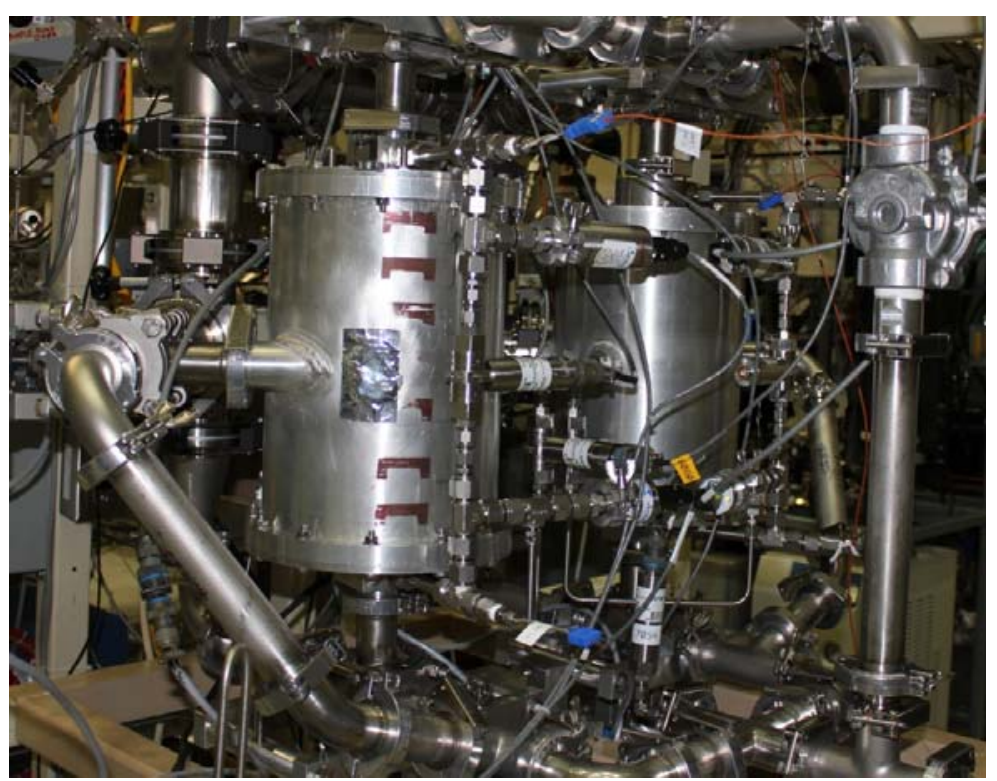

Figure 6 SBAR Test Article Integrated with the SES

temperature at the top, center, and bottom as well. Delta pressure sensors measure the pressure drop across the bed layers during the adsorb half-cycle. Figure 7 is the schematic of the SES as configured for testing the SBAR system in the 2-bed configuration.

\section{Modifications, Tests, and Results}

The molecular sieve material utilized in the SBAR system tends to not desorb all adsorbed water without added heat. Over time this water will gradually decrease $\mathrm{CO}_{2}$ removal performance and the material must then be thermally regenerated to regain full removal performance. Due to this slow degradation in performance, the test approach was to fully account for this characteristic. More than 20 mission length test cases have been completed during this program and a significant improvement in performance has been observed as modifications to the SBAR configuration and operation have been implemented. This improvement has been accomplished without increasing the mass or volume of the proposed spacecraft ARS and is primarily due to implementation of a means for diverting a portion of the ARS flow around the 5A zeolite layer.

Initially, the system requirements and mission scenarios were driven by the requirements of the Constellation Program so early testing primarily addressed the Exploration Life Support Requirements Document ${ }^{4}$ while complying with the specific requirements of the Constellation Program Human-Systems Integration Requirements (HSIR) $)^{5}$. For all missions the SBAR system must provide $100 \%$ removal of Metabolic $\mathrm{CO}_{2}$ and $\mathrm{H}_{2} \mathrm{O}$. The HSIR 
limits for $\mathrm{CO}_{2}$ exposure allow time limited excursions above a partial pressure of 5 Torr but the goal is for the partial pressure to remain $<5$ Torr for all nominal operations.

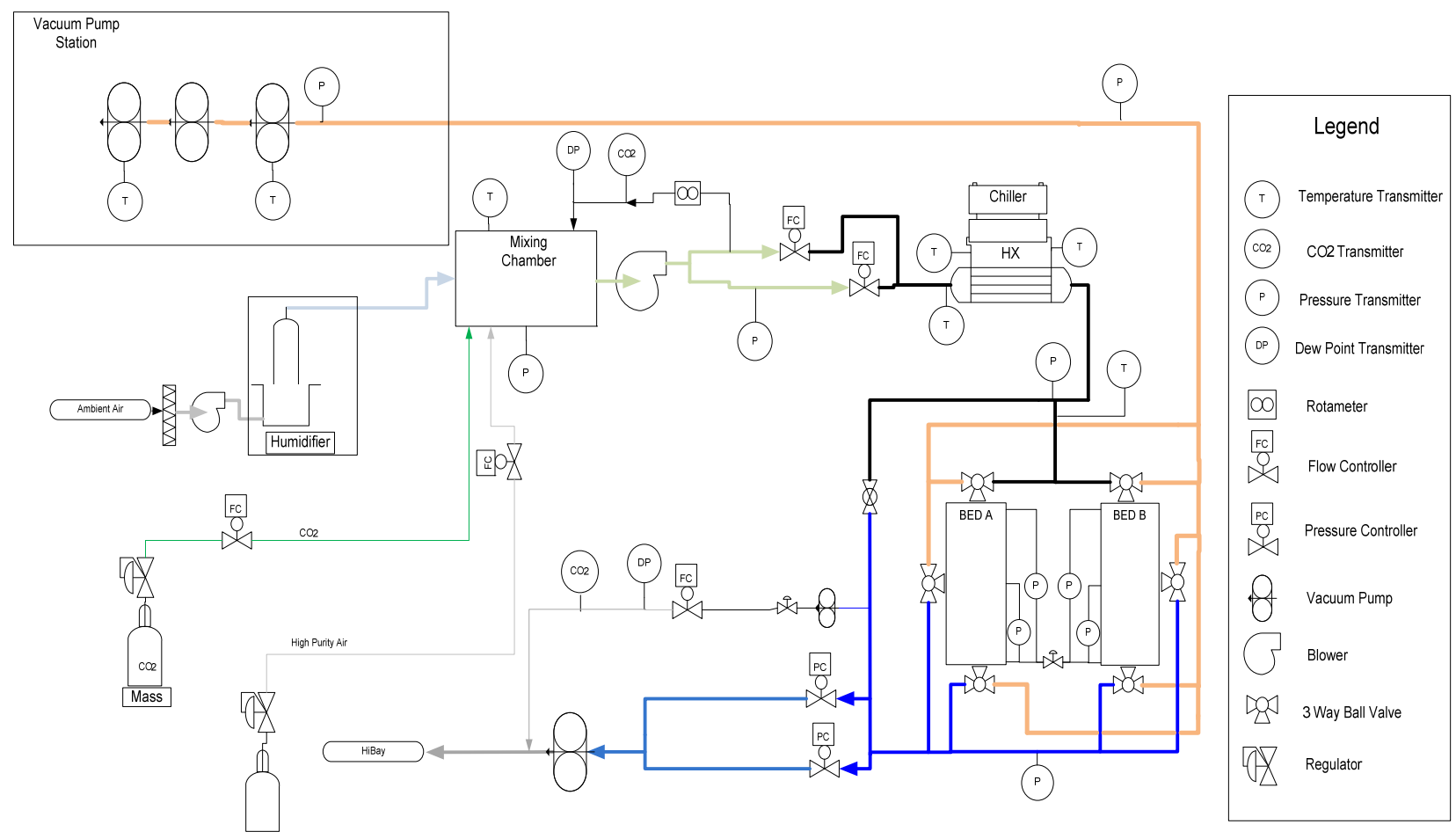

Figure 7 Spacecraft ECLSS Simulator (SES) Schematic

The HSIR specified tolerance range for relative humidity is between $25 \%$ and $75 \%$ except during temporary transient excursions. However, condensation in the spacecraft cabin should be prevented, which places an upper limit on the cabin dew point. The Orion CEV baseline ECLSS incorporated a temporarily condensing heat exchanger to capture and hold excess moisture. In this architecture, the ARS is required to maintain a nominal cabin dew point below $10^{\circ} \mathrm{C}\left(50^{\circ} \mathrm{F}\right)$ while limiting transient excursions to below $14.4^{\circ} \mathrm{C}\left(58^{\circ} \mathrm{F}\right)$.

The SBAR system removes nearly $100 \%$ of the water vapor that enters it. Because of this removal performance, an SBAR system can potentially be operated with flow rates that completely eliminate the need for handling condensation in the heat exchanger. To test this configuration, the test cases described herein were operated at flow rates sufficient to maintain the dew point below $7^{\circ} \mathrm{C}\left(45^{\circ} \mathrm{F}\right)$. This dew point is below the temperature of the coolant loop and condensation in the system heat exchanger would be prevented. This requires significantly higher ARS flow rates to maintain the lower dew point and would tend to accelerate the $\mathrm{CO}_{2}$ removal performance degradation due to water load on the $5 \mathrm{~A}$ zeolite layer.

The metabolic loads applied for the test cases at nominal temperatures were obtained from the HSIR. For offnominal temperature operation, the applied metabolic loads were as per the Shuttle Operational Data Book (ODB $)^{6}$. A select few of the test cases performed are described herein.

\section{A. Fixed Conductance Bypass Testing}

Early testing showed that limiting the flow through the $\mathrm{CO}_{2}$ removing layer increases removal performance while also decreasing water adsorption on the $5 \mathrm{~A}$ zeolite material. Therefore a method for diverting a portion of the total bed flow around the $5 \mathrm{~A}$ zeolite material was identified as a means for a significant improvement in $\mathrm{CO}_{2}$ removal over longer durations. The initial approach was to install bypass plumbing with a fixed conductance that allowed approximately $55 \%$ of the total ARS flow to bypass the lower layers of the bed at nominal flow rates.

The test case chosen duplicated an extended a CEV lunar transit scenario that had been previously run without the lower bed bypass configuration. The scenario evaluated the capability for the SBAR to control cabin $\mathrm{CO}_{2}$ and $\mathrm{H}_{2} \mathrm{O}$ during the metabolic transients experienced during crew exercise activity while holding a nominal $7{ }^{\circ} \mathrm{C}\left(45^{\circ} \mathrm{F}\right)$ dew point. The second part of the scenario evaluated the capability of a single SBAR system with the fixed bypass to control the $\mathrm{CO}_{2}$ and $\mathrm{H}_{2} \mathrm{O}$ for a full 4 crewmember $(\mathrm{CM})$ crew for an extended period. 
Test Parameters:

- Mission Simulation $-\mathrm{CO}_{2}$ and $\mathrm{H}_{2} \mathrm{O}$ partial pressures are determined real-time as a function of the SBAR performance and the current metabolic load

- Transient metabolic loading per the HSIR - daily exercise for the outgoing mission and then for the return mission, with the full load (except exercise periods) on a single SBAR unit

- Cabin volume - 12,176 liters $\left(430 \mathrm{ft}^{3}\right)$

- Cabin temperature $-21.1^{\circ} \mathrm{C}\left(70^{\circ} \mathrm{F}\right)$

- Flow rates - adjusted to obtain an average $7.25^{\circ} \mathrm{C}\left(45^{\circ} \mathrm{F}\right)$ dew point

- Pressure - 525 Torr (10.2 psia)

- Fixed conductance bypass - initially $\approx 55 \%$ bypassed then $\approx 45 \%$ flow around lower bed layers

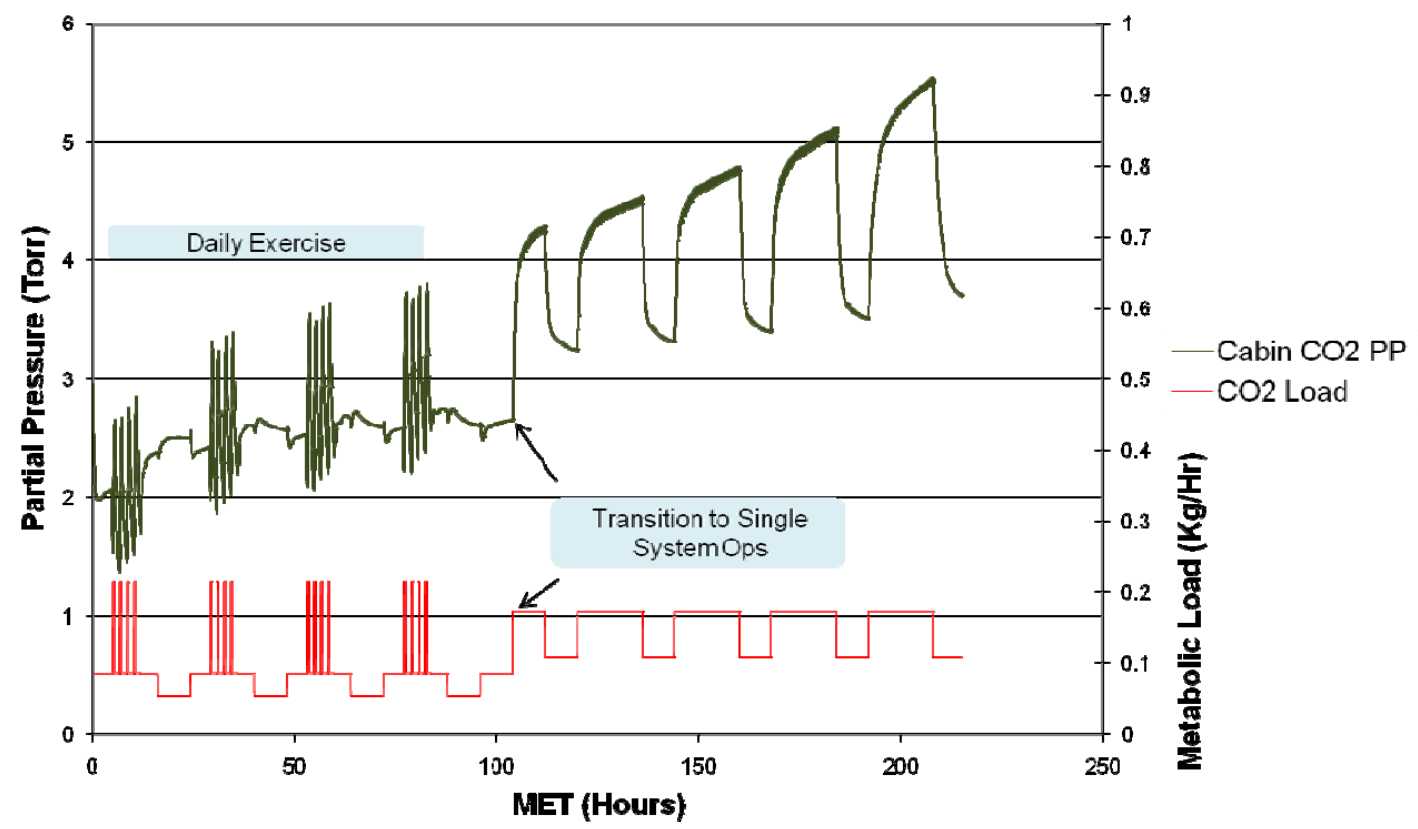

Figure $8 \mathrm{CO}_{2}$ Control - No 5A Bypass

Figure 8 shows the $\mathrm{CO}_{2}$ conditions throughout the mission for an SBAR system without the bypass implemented. As the full crew induced metabolic load was handled by the single unit, the $\mathrm{CO}_{2}$ removal performance progressively degraded. By approximately 175 hours Mission Elapsed Time (MET), the $\mathrm{CO}_{2}$ level had risen to the nominal 5 Torr limit and then increased significantly during the next nominal wake period.

Figure 9 shows the $\mathrm{CO}_{2}$ conditions throughout the mission for an SBAR system with the fixed conductance bypass implemented. The $\mathrm{CO}_{2}$ levels during exercise remained below 5 Torr, however, after transition to single unit operations the simulated cabin $\mathrm{CO}_{2}$ level went above 5 Torr. This indicated that the fixed bypass was not providing sufficient flow through the $\mathrm{CO}_{2}$ removing layers of the bed to remove the full $\mathrm{CO}_{2}$ production of 4 crewmembers (CMs). At $\approx 190$ hours MET, the plumbing was adjusted so that the total flow bypassed around the lower layers was decreased from $\approx 55 \%$ to $\approx 45 \%$. The simulated cabin $\mathrm{CO}_{2}$ partial pressure then dropped and remained below the nominal 5 Torr limit until 340 hours MET. 


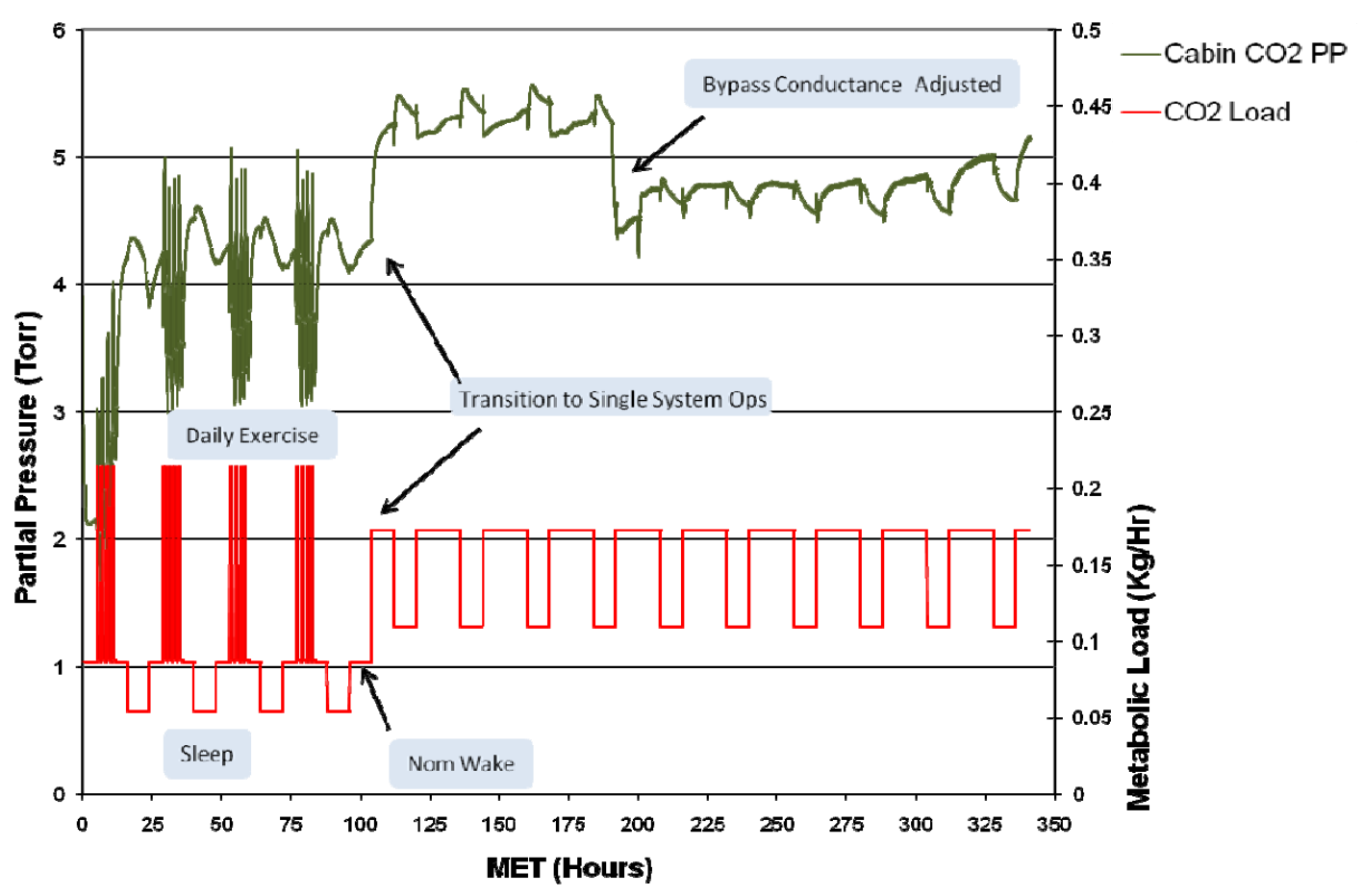

Figure $9 \mathrm{CO}_{2}$ Control - Fixed 5A Bypass

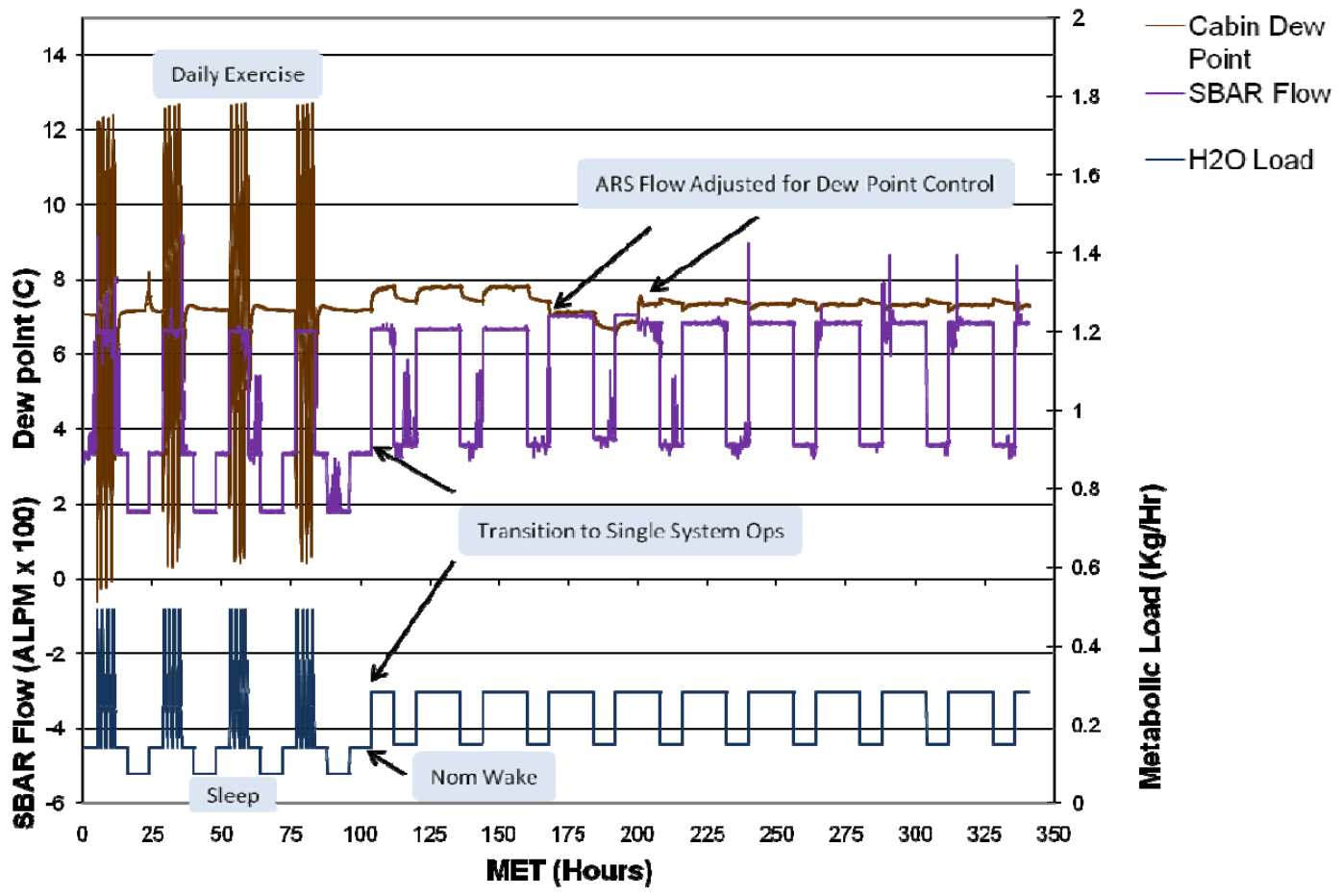

Figure $10 \mathrm{H}_{2} \mathrm{O}$ Control - Fixed 5A Bypass

Figure 10 depicts the humidity conditions in the cabin over the mission timeline. The small volume of the cabin allowed transient dew point excursions to $>12^{\circ} \mathrm{C}\left(53.5^{\circ} \mathrm{F}\right)$ for short periods of less than 20 minutes. The bypass flow did allow some water vapor breakthrough during the higher flow rates associated with single unit operation 
during the wake periods. To compensate, the SBAR flow rate was increased by $\approx 2 \%$ during the wake periods with single unit operation.

The fixed bypass implementation effectively doubled the duration that a single system would meet the removal requirements for the full $4 \mathrm{CM}$ complement. However, the test results did indicate that a bypass implementation that relied on a fixed conductance in the plumbing around the $\mathrm{CO}_{2}$ adsorbing layers of the bed would not result in optimal performance.

\section{B. Testing with Actively Controlled Bypass Flow}

The results of the fixed conductance bypass testing showed that a method for actively controlling the bypass would be needed to achieve optimum results over the wide range of potential cabin conditions and metabolic loads. An approach to utilize three-way ball valves for control of the bypass around the $\mathrm{CO}_{2}$ absorbing layers a function of cabin $\mathrm{CO}_{2}$ partial pressure was developed and implemented. A series of test cases was performed to evaluate the potential performance improvements of an actively controlled bypass SBAR system. A goal of these tests was to verify that the level of performance whereby a single operating SBAR unit is sufficient to remove the nominal metabolic $\mathrm{H}_{2} \mathrm{O}$ and $\mathrm{CO}_{2}$ produced by the full crew of 4 for the entire mission duration. This capability would allow the second SBAR unit to remain as a redundant standby system.

Test Parameters:

- Mission Simulation $-\mathrm{CO}_{2}$ and $\mathrm{H}_{2} \mathrm{O}$ partial pressures are determined real-time as a function of the SBAR performance and the current metabolic load

- Metabolic loading per the HSIR - nominal metabolic wake and sleep loads removed with a single operating SBAR unit

- Cabin volume - 12,176 liters $\left(430 \mathrm{ft}^{3}\right)$

- Flow rates - adjusted to maintain a dew point $<7^{\circ} \mathrm{C}\left(45^{\circ} \mathrm{F}\right)$

- Cabin temperature $-21.1^{\circ} \mathrm{C}\left(70^{\circ} \mathrm{F}\right)$

- Pressure - 525 Torr (10.2 psia)

- No Bypass flow - suit loop flow passes through entire SBAR bed

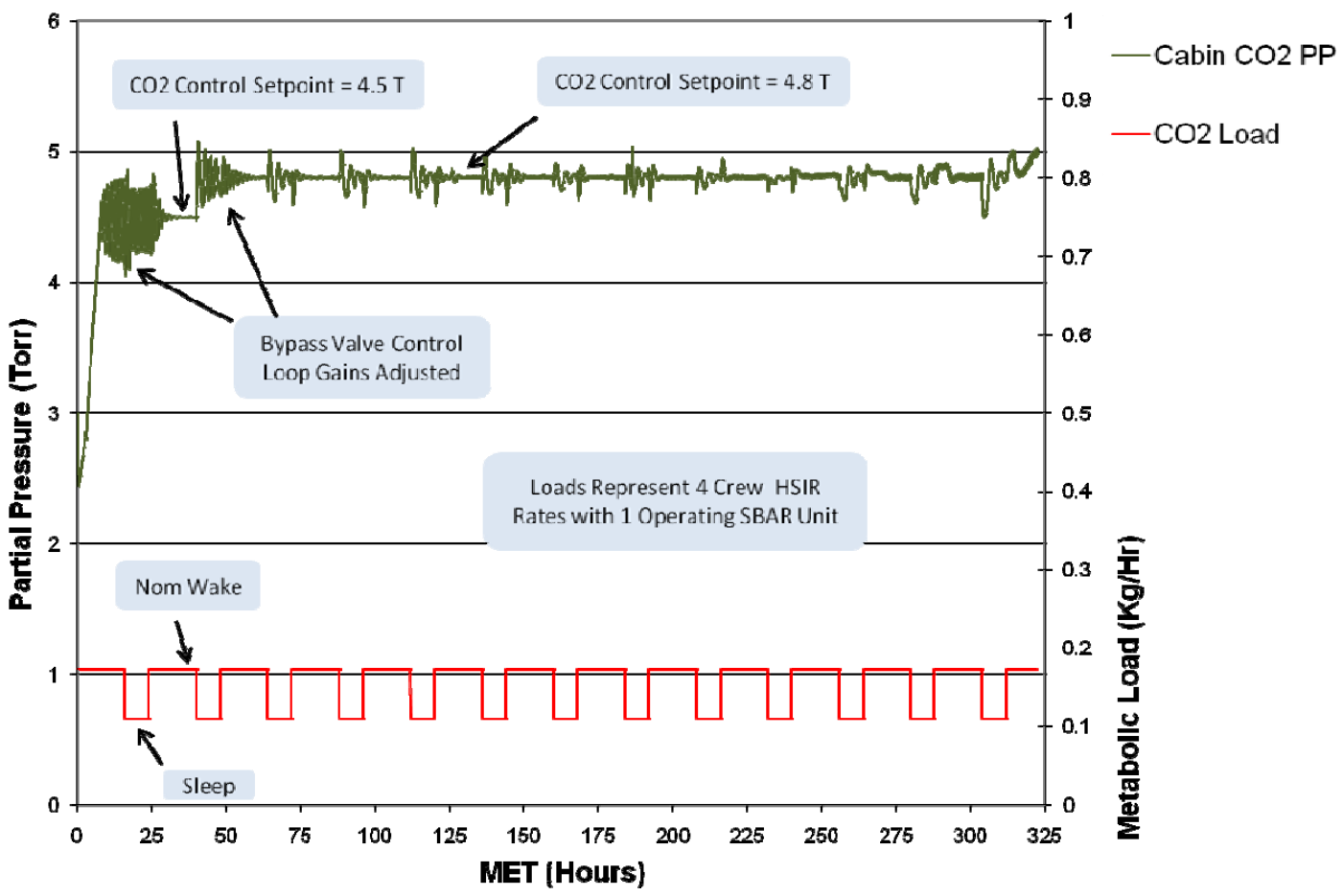

Figure $11 \mathrm{CO}_{2}$ Control Active Bypass 
Figure 11 shows the $\mathrm{CO}_{2}$ partial pressure throughout the mission timeline of a test case evaluating the capability of a single SBAR unit with an actively controlled bypass flow implementation. The initial setpoint for $\mathrm{CO}_{2}$ partial pressure control was 4.5 Torr and the settings of the PID loop allowed oscillation around the set point. The gain values were then adjusted to decrease the magnitude of the oscillations. After stable control was achieved, the setpoint was then changed to 4.8 Torr. Oscillations around the setpoint were again observed and the gain values were readjusted to better tune the control loop. Small oscillations around the setpoint continued, particularly during the sleep periods when the total flow was lower. Although further fine-tuning of the control loop could have further decreased the magnitude of these oscillations, they had minimal impact upon the test and no further adjustments were made during this test case.

Figure 12 shows the cabin humidity levels during the test. The dew point early in the a test was somewhat higher than predicted because a small amount of water vapor is not captured in the upper portion of the bed, leading to less than $100 \%$ removal efficiency during high bypass ratio operation. To compensate for this, the total flow rate was raised $5 \%$ and the resulting dew point fell below the desired $7{ }^{\circ} \mathrm{C}\left(45^{\circ} \mathrm{F}\right)$.

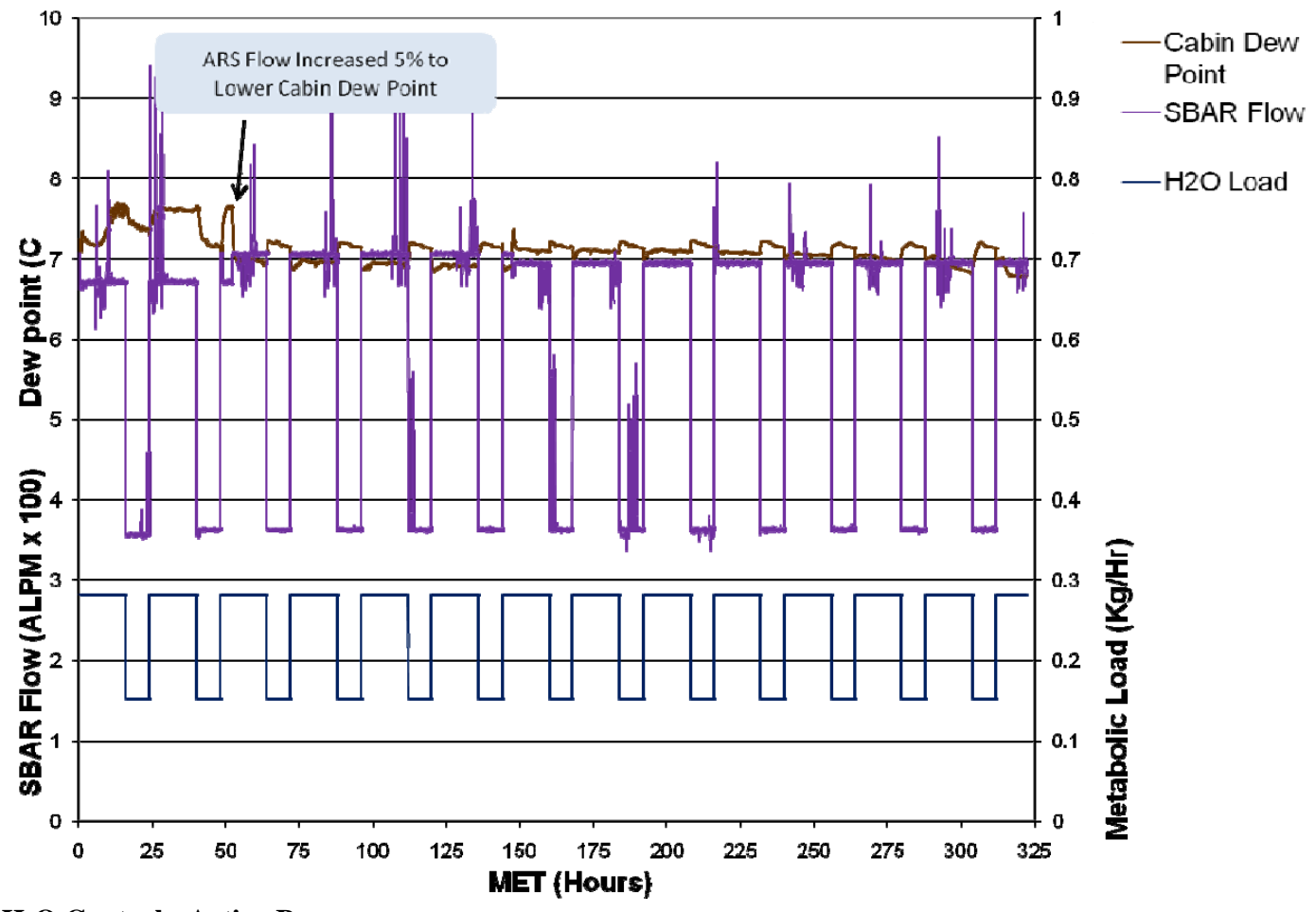

Figure $12 \mathrm{H}_{2} \mathrm{O}$ Control - Active Bypass

This test case demonstrated that the approach for controlling $\mathrm{CO}_{2}$ levels in the cabin independently of the requirements for humidity control was viable. The control algorithms for maintaining a constant $\mathrm{CO}_{2}$ partial pressure could have been optimized further but the level of control clearly met requirements. The test also verified that a single SBAR unit could remove the metabolic loads generated by the full crew for an entire mission duration.

This test case demonstrated that the approach for controlling $\mathrm{CO}_{2}$ levels in the cabin independently of the requirements for humidity control was viable. The control algorithms for maintaining a constant $\mathrm{CO}_{2}$ partial pressure could have been optimized further but the level of control clearly met requirements. The test also verified that a single SBAR unit could remove the metabolic loads generated by the full crew for an entire mission duration.

\section{Testing with Complex Metabolic Load Scenarios}

Several test cases to evaluate the SBAR system over a wide range of metabolic load conditions, mission durations, SBAR VSA cycle rates, and cabin pressures were also performed. The range of metabolic load conditions varies from quite high during the periods when the crew are donning or doffing their suits to quite minimal such as during Extra-Vehicular Activity (EVA) periods. A representative test case is one that represented a standard lunar lander sortie mission with daily EVAs. 
Test Parameters:

- Mission Simulation $-\mathrm{CO}_{2}$ and $\mathrm{H}_{2} \mathrm{O}$ partial pressures are determined real-time as a function of the SBAR performance and the current metabolic load

- Cabin volume - 12,176 liters $\left(430 \mathrm{ft}^{3}\right)$

- Flow rates - set to obtain $\leq 7.5^{\circ} \mathrm{C}\left(45.5^{\circ} \mathrm{F}\right)$ dew point

- Cabin temperature - nominally $21.1^{\circ} \mathrm{C}\left(70^{\circ} \mathrm{F}\right)$ except at $27^{\circ} \mathrm{C}\left(80.3^{\circ} \mathrm{F}\right)$ during suit donning and doffing

- Pressure - 414 Torr (8 psia)

- SBAR cycle time - 6.5 - 25 minutes depending on $\mathrm{H}_{2} \mathrm{O}$ load

- Bypass flow - actively controlled $-\mathrm{CO}_{2}$ pp set point at 4.8 Torr

The metabolic loads applied for this test case represented those expected during a nominal lunar sortie mission with daily EVAs. The metabolic load timeline for the entire mission is shown in Figure 13while detailed view of a 30 hour period is shown in Figure 14. The very high metabolic loads associated with the crew donning and doffing the suits require that the second SBAR unit, which is nominally in non-operational standby, be temporarily brought on line. For the expected don/doff loads a conservative approach was taken to calculate loads based on an average metabolic rate of $179 \mathrm{~W}(612.5 \mathrm{BTU} / \mathrm{Hr})$ in a $27^{\circ} \mathrm{C}$ cabin which represents $2 \mathrm{CMs}$ actively don/doffing suits while 2 maintain nominal metabolic rates. For this simulation these loads were applied for an hour both pre and post EVA. In addition, these don/doff loads were applied for the full hour even when the EVA being simulated included less than the full $4 \mathrm{CM}$ complement.

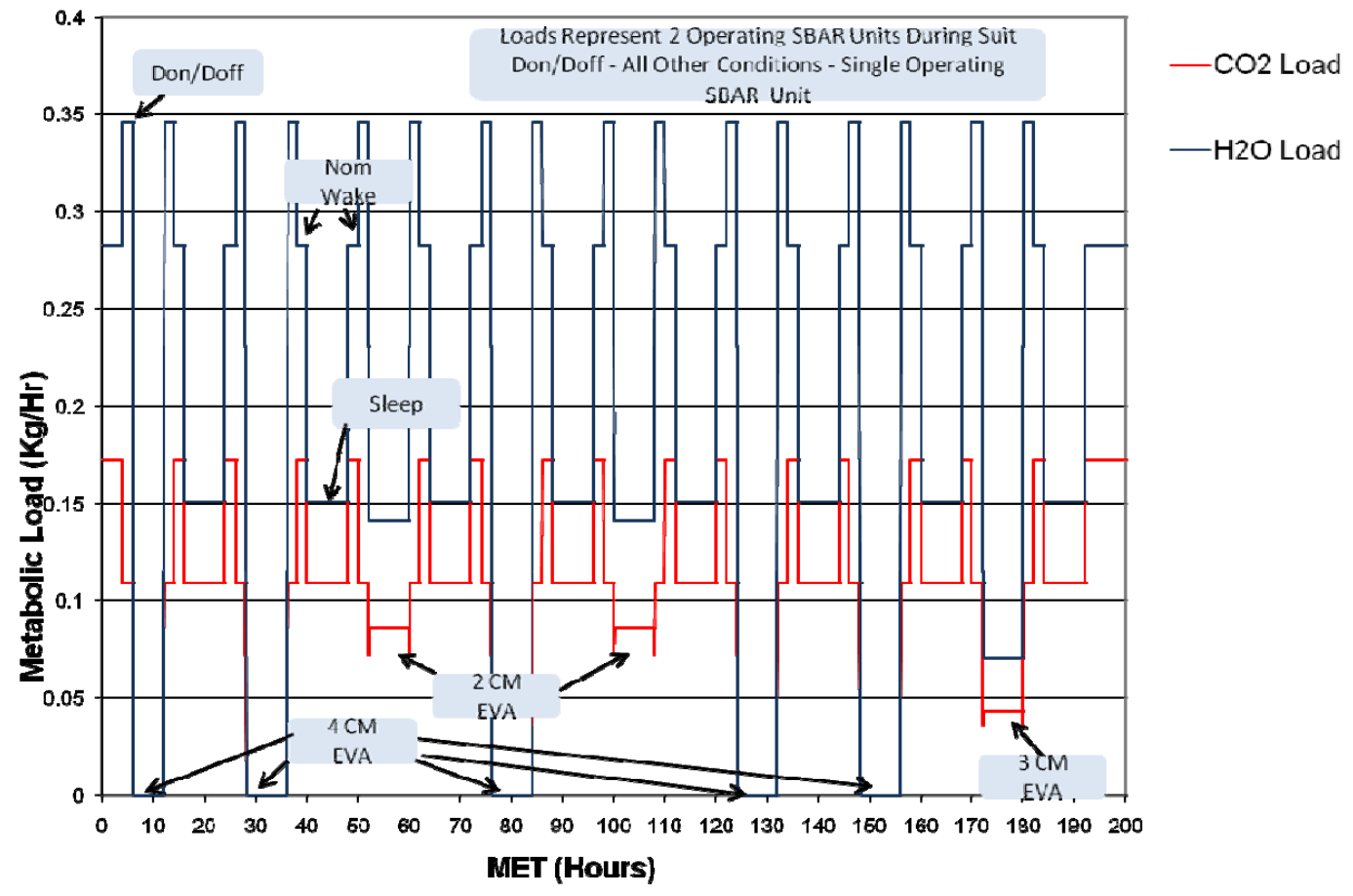

Figure 13 Metabolic Profile of Lunar Lander Sortie w/EVA

Figure 15 shows the $\mathrm{CO}_{2}$ levels throughout the mission simulation. While there was some oscillation of $\mathrm{CO}_{2} \mathrm{pp}$ around the 4.8 Torr set point, the cabin conditions remained well within HSIR limits. The amplitude of the oscillation was greater during the periods of low flow associated with less than the full crew in the cabin. It is expected that implementation of a valve system optimized for SBAR operation and further refinement of the control algorithms would decrease these oscillations. The transient conditions resulting from the suit donning drove the $\mathrm{CO}_{2}$ pp lower than the setpoint at the start of the EVA which then contributed to the magnitude of the oscillations after the EVA although cabin $\mathrm{CO}_{2}$ pp requirements continued to be met. 


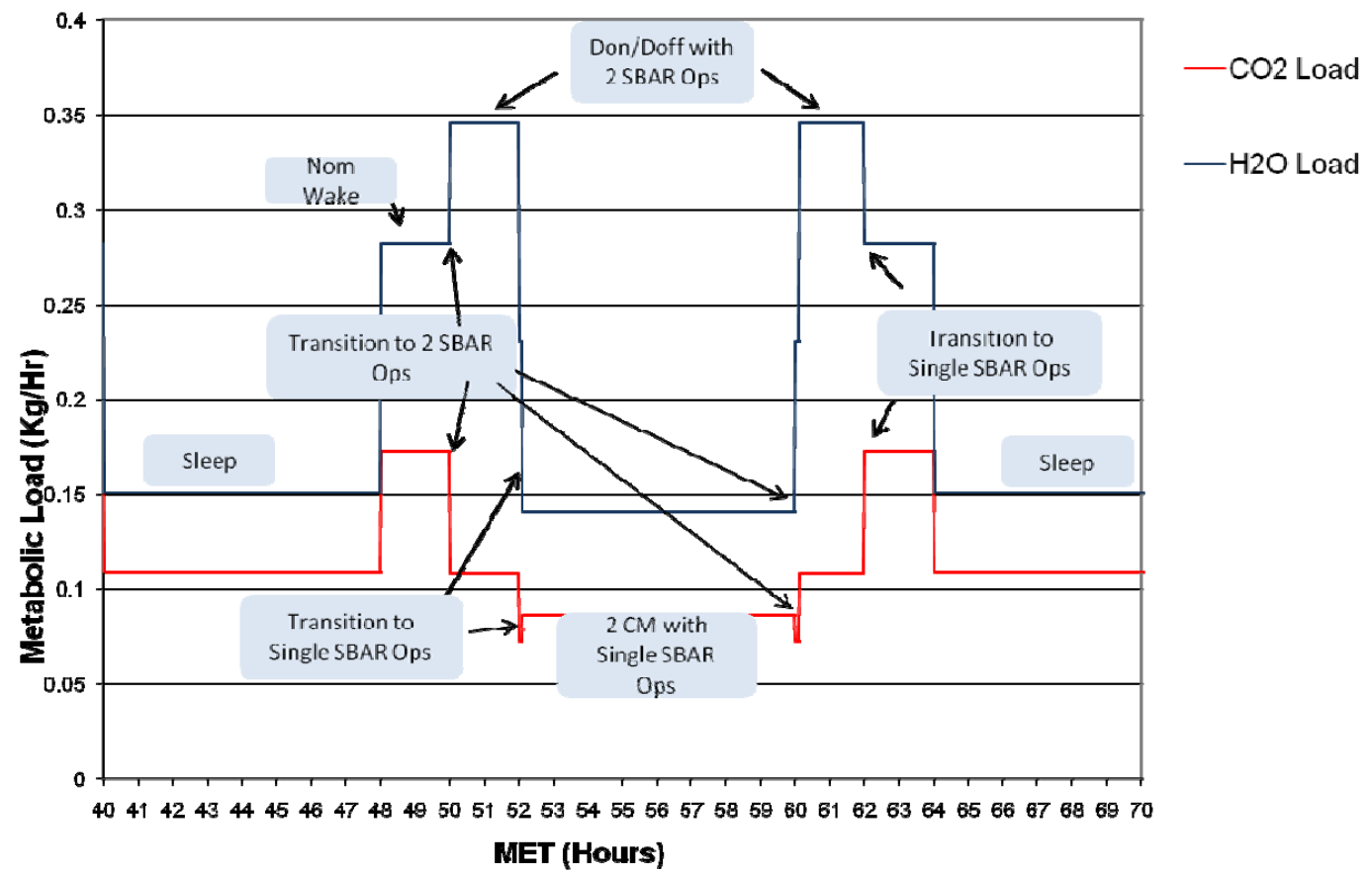

Figure 1430 Hour Detail of Metabolic Profile

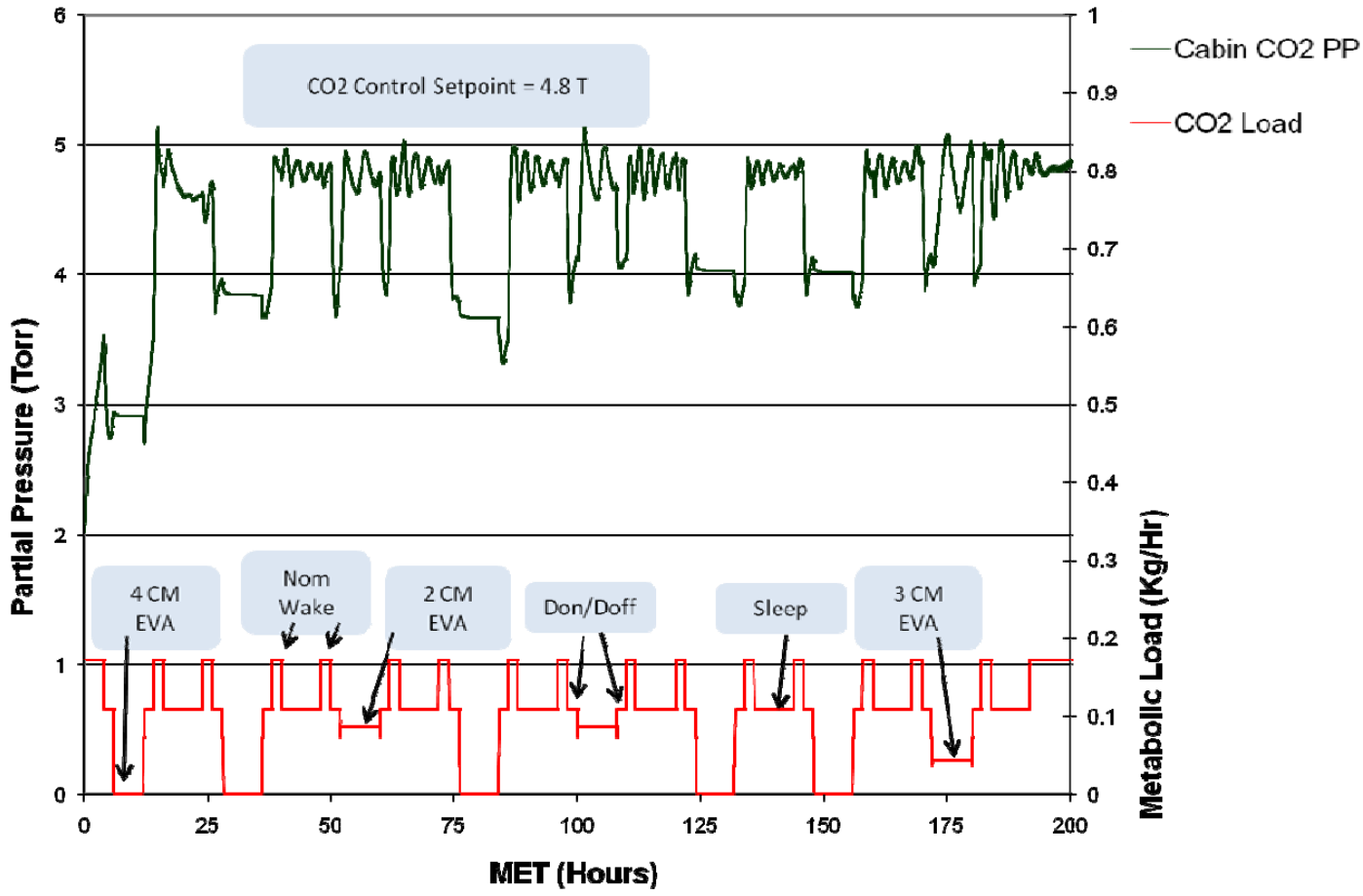

Figure $15 \mathrm{CO}_{2}$ Levels - Lunar Lander Sortie w/EVA

Figure 16 shows the humidity levels in the cabin during the test. As observed previously, single pass water vapor removal efficiency was less than $100 \%$ during the high bypassed flow associated with the don/doff loads. As a result, there were short excursions above the desired $7.5^{\circ} \mathrm{C}\left(45.5^{\circ} \mathrm{F}\right)$ dew point. The dew point remained below $7.65^{\circ}$ 
$\mathrm{C}\left(45.8^{\circ} \mathrm{F}\right)$ for the entire test. The SBAR cycle rate was varied during the mission to minimize gas usage while limiting the maximum amount of water load in the bed to $<20 \mathrm{~g}$ per Half Cycle (HC). The longest cycle time of 25 minutes was applied during an EVA period in which a single CM remained in the LL cabin.

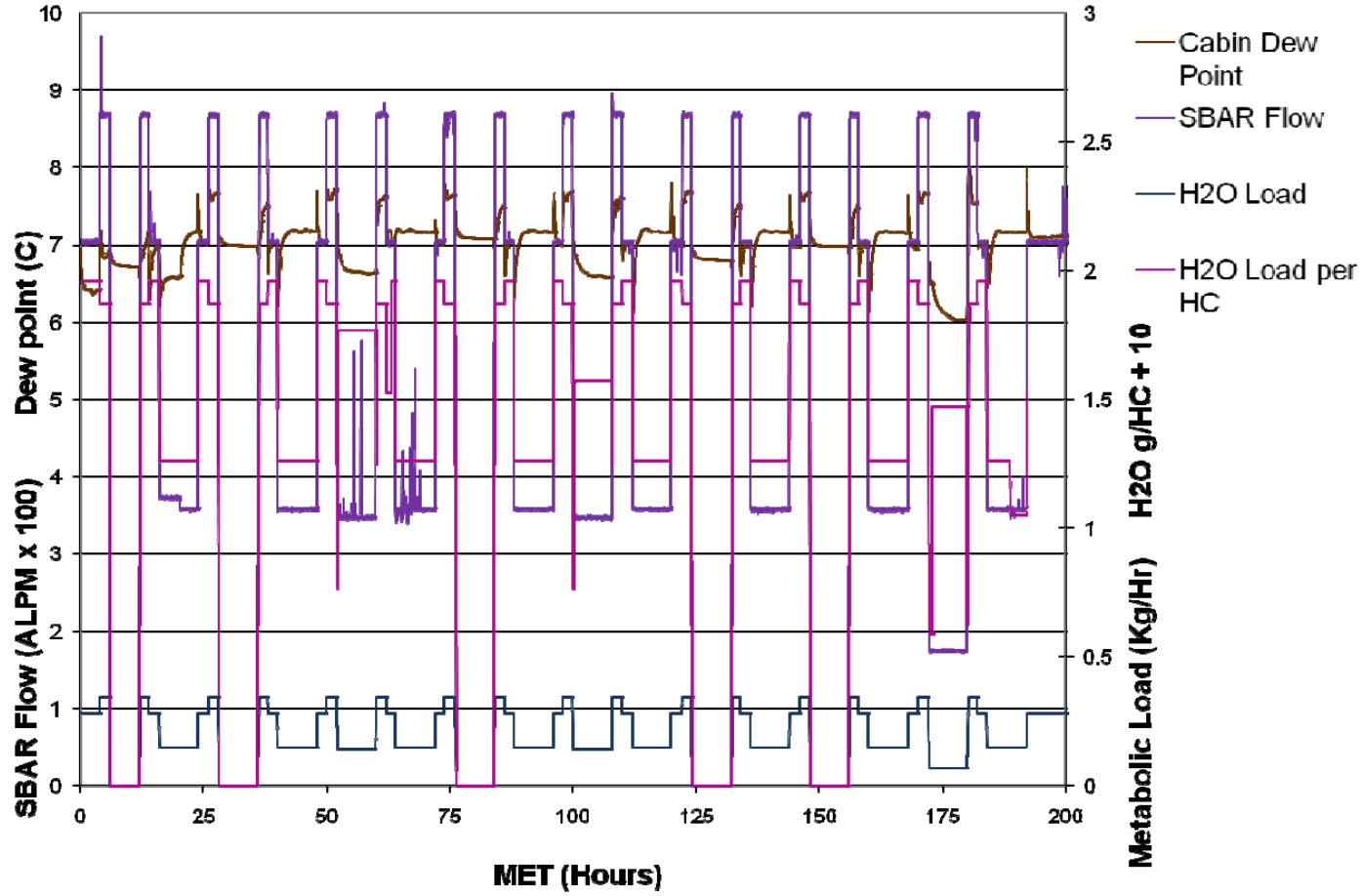

Figure $16 \mathrm{H}_{2} \mathrm{O}$ Levels - Lunar Lander Sortie w/EVA

\section{Testing to the Launch Abort Scenario}

There are times that a source of vacuum or purge gas is not available during SBAR operation thereby preventing removal of the adsorbed $\mathrm{CO}_{2}$ and water during the desorption half cycle. However, the $\mathrm{CO}_{2}$ and humidity control functions are still required. These events normally occur only during the vehicle ascent and reentry phases of the mission. For the ascent phase, the duration of this mode of operation is from the time that the umbilical is disconnected until the vehicle reaches an altitude where the atmospheric pressure is minimal. For reentry operation, the duration extends from the initial encounter with the atmosphere until post landing when the cabin can receive outside air. While the reentry case is longer, both of these modes of operation are expected to be of short duration. The special case of a launch abort scenario has the potential for requiring operation without a vacuum source for a much longer period. A test case to assess the capability of the SBAR system to maintain safe conditions for the crew during the worst case launch abort scenario was performed. If a safe level of $\mathrm{CO}_{2}$ partial pressure could be maintained for a sufficient duration than there would be no need for an additional emergency $\mathrm{CO}_{2}$ removal capability.

Test Parameters:

- Suit Loop Simulation $-\mathrm{CO}_{2}$ and $\mathrm{H}_{2} \mathrm{O}$ partial pressures in the return from the suits are determined real-time as a function of the SBAR performance and the suited crew metabolic load

- Metabolic Load-2 CM per SBAR with nominal suited CM loads (51 g/hr $\mathrm{CO}_{2} \& 41 \mathrm{~g} / \mathrm{hr} \mathrm{H} \mathrm{H}_{2} \mathrm{O}$ ) for each CM

- Flow rate -283 alpm $(10 \mathrm{cfm})$

- Suit return temperature $-21.1^{\circ} \mathrm{C}\left(70^{\circ} \mathrm{F}\right)$

- Pressure - 760 Torr (14.7 psia)

- SBAR cycle time - 10 minutes 


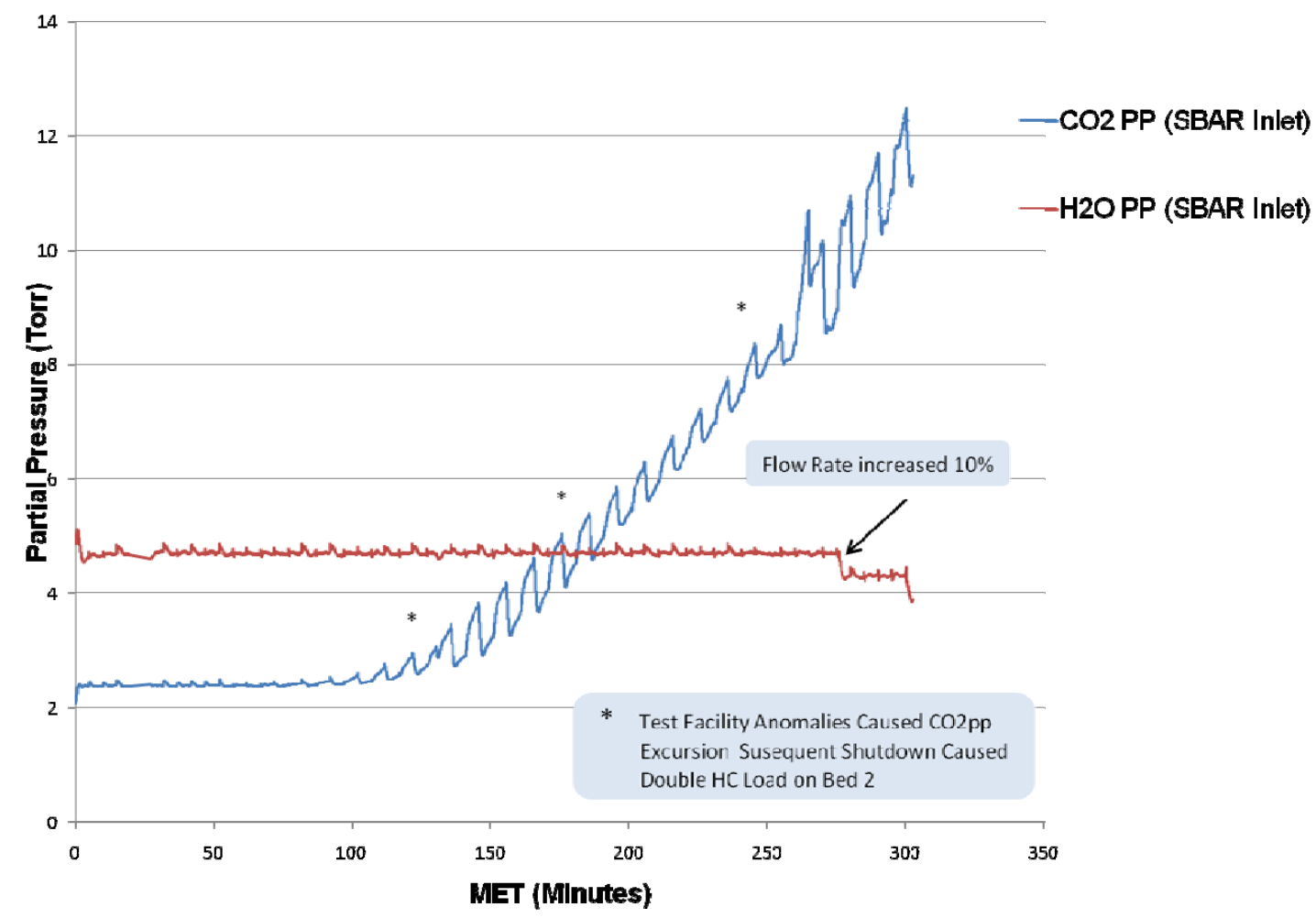

Figure $17 \mathrm{CO}_{2} \& \mathrm{H}_{2} \mathrm{O}$ Control w/o Desorb Vacuum or Purge

The crew will be in their suits during the launch and reentry phases of the mission. The metabolic loads applied for this test case represented those expected with the crew in their suits for the duration of the simulation. The flow rate through the suit loop is set by the requirement to deliver $142 \mathrm{lpm}(5 \mathrm{cfm})$ to each suit. Figure 17 shows a plot of the $\mathrm{CO}_{2}$ and $\mathrm{H}_{2} \mathrm{O}$ partial pressures in the return to the SBAR system from the suits. Since this is the same flow as the outlet of the suits, the levels within the helmet would be somewhat lower. No attempt to model the mixing within the helmets was made for this test.

Test facility anomalies occurred during the performance of this test with the effect of uneven loading between the two beds of the SBAR unit. The second bed received a significantly larger amount of adsorption flow then the first bed. Since there was no available vacuum for the desorption half cycle to remove the $\mathrm{CO}_{2}$ and $\mathrm{H}_{2} \mathrm{O}$, it accumulated in the bed causing the observed difference in removal performance as seen in the plot. Without the test facility anomalies the resultant suit loop $\mathrm{CO}_{2}$ partial pressure would be expected to be the average of the two half cycles.

The HSIR specifies off-nominal and emergency levels and durations to assure crew safety. When the test was terminated after 300 minutes (5 hours) the $\mathrm{CO}_{2}$ partial pressure was peaking near 12 Torr - well within the offnominal range of $10-15$ Torr and safe for up to 4 hours duration. At 275 minutes into the test the flow was increased by $10 \%$ to observe the effect. The increase in flow had minimal effect on the $\mathrm{CO}_{2}$ removal performance although the humidity removal increased proportionately.

\section{E. Operation with Other Potential Manned Spacecraft and Missions}

Several test cases were performed to evaluate the SBAR technology for possible application in vehicles that are currently under consideration for future manned missions. These applications include an exploration vehicle where the mission would be of a longer duration and the ECLSS would incorporate a condensing heat exchanger for capturing water for reclamation. Another application under consideration would be in a crew transport vehicle for ferrying as many as seven crewmembers to the ISS.

\section{Application in a Water-Save ECLSS Architecture}

SBAR operations previously evaluated were in "water dump" mode, where captured water is not retained and is dumped overboard to space. The objective for this test case was to evaluate $\mathrm{SBAR}^{\mathrm{CO}} \mathrm{O}_{2}$ removal performance when integrated with an ARS that incorporates water saving technology where the water is recovered for reuse. This is a 
likely configuration for longer duration missions/vehicles. While no particular ARS architecture was identified to specify the conditions for this test, any such ARS will produce dryer SBAR inlet conditions. All previous testing has indicated that the $\mathrm{CO}_{2}$ removal capacity would remain high for an extended duration when the metabolic $\mathrm{H}_{2} \mathrm{O}$ does not have to be removed by the VSA process. For this test case the inlet dew point was set to $-17.8^{\circ} \mathrm{C}\left(-6.7^{\circ} \mathrm{F}\right)$ which is compatible with test results of a bulk drying assembly currently under development for use in a water-save ARS ${ }^{7}$. This test was a characterization test case and inlet conditions were held constant with the initial ARS flow set to a rate sufficient to remove the metabolic $\mathrm{CO}_{2}$ from a cabin with 6 crewmembers when the removal efficiency is $\geq$ $85 \%$.

Test Parameters:

- $\mathrm{CO} 2$ partial pressure -5 Torr

- Humidity $-21.5^{\circ} \mathrm{C}\left(-6.7^{\circ} \mathrm{F}\right)$ dew point,

- Temperature $-21.1^{\circ} \mathrm{C}\left(70^{\circ} \mathrm{F}\right)$

- Pressure - 760 Torr (14.7 psia)

- Flow rate $-410 \mathrm{slpm}(14.5 \mathrm{scfm})$

- SBAR cycle time - 8.0 minutes

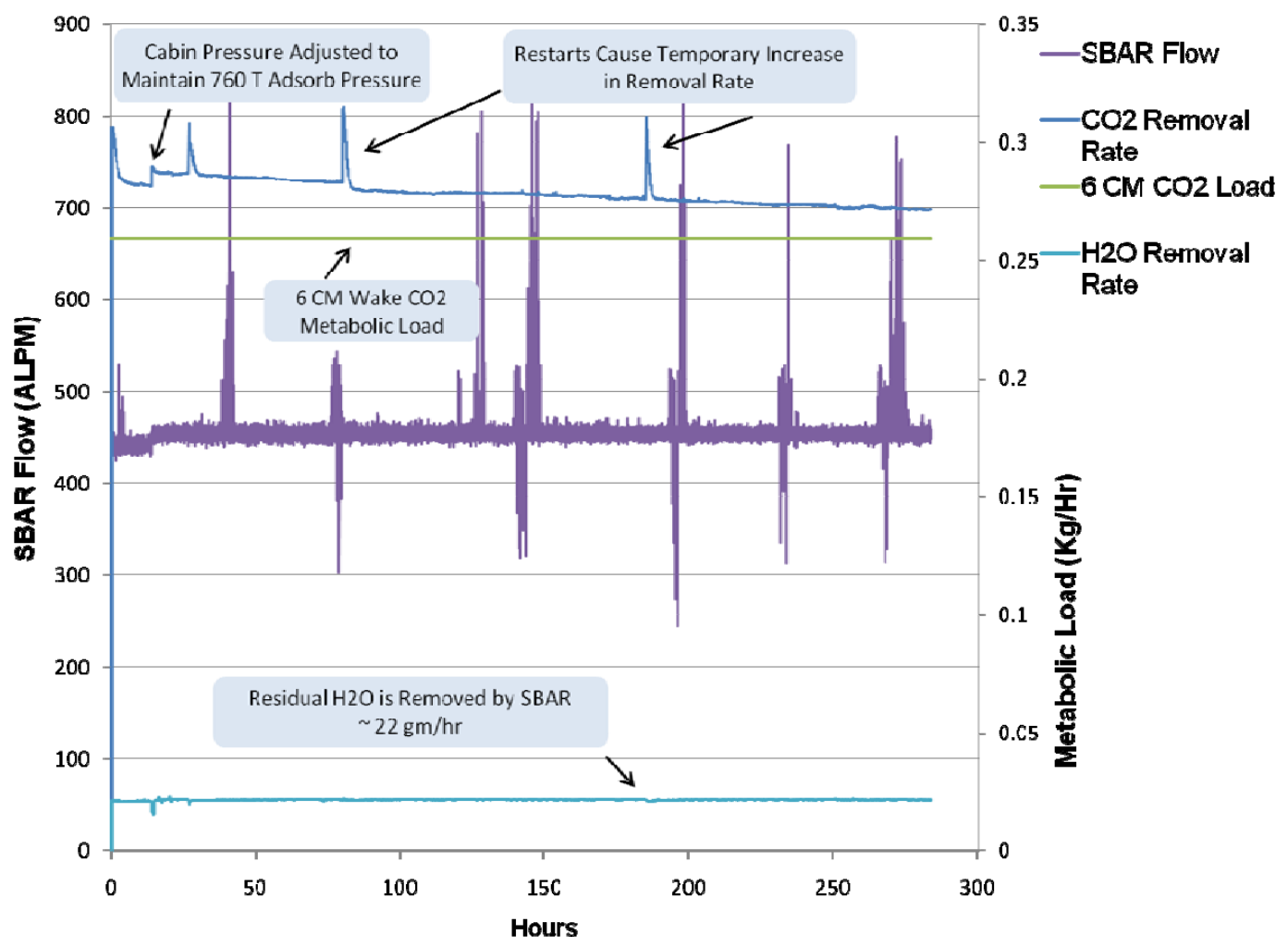

Figure $18 \mathrm{CO}_{2}$ Removal Performance in Water Save ARS

Figure 18 shows the removal performance over the duration of the test. Initially, the bed adsorb pressure was greater than the nominal 760 Torr and the pressure was adjusted resulting in the small increase in volumetric flow rate as evidenced on the plot. There were test facility shutdowns for various reasons and the restart procedure led to the short spikes of the increased removal rates shown on the plot. At the flow rate set for this test case a gradual decrease in $\mathrm{CO}_{2}$ removal performance was observed. Although the test was terminated at 284 hours, a trend analysis of the decrease in performance indicated that an SBAR unit operating with these inlet conditions would remove the metabolic $\mathrm{CO}_{2}$ from a cabin with $6 \mathrm{CM}$ for more than 600 hours before requiring thermal regeneration. 


\section{Application in a 7 Crewmember Transport Vehicle}

The objective of this test was to evaluate SBAR ability to control cabin $\mathrm{CO}_{2}$ and $\mathrm{H}_{2} \mathrm{O}$ when integrated into a crew transport vehicle with a 7 crewmember capacity. This crew capacity is outside of current mission requirements but is expected to be a requirement for the yet to be fully defined transport vehicle for ferrying crew to the ISS. To assure safety margins, a new operational approach was evaluated for this case where a thermal regeneration would be performed during the crew sleep periods. While this mode of operation would allow missions of unlimited duration, the SBAR unit not being regenerated is required to handle the sleep loads for all $7 \mathrm{CM}$ for the duration of the thermal regeneration. The entire 8 hour sleep period was allocated for the SBAR regeneration although the required time for regeneration should be significantly less. To assure operational margins, the metabolic loads were assumed to be at the higher $27^{\circ} \mathrm{C}\left(80.6^{\circ} \mathrm{F}\right)$ level for the duration of the sleep period.

Test Parameters:

- Mission Simulation - $\mathrm{CO}_{2}$ and $\mathrm{H}_{2} \mathrm{O}$ partial pressures are determined real-time as a function of the SBAR performance and the current metabolic load

- Cabin volume $-18,406$ liters $\left(650 \mathrm{ft}^{3}\right)$

- Flow rates - adjusted to obtain $\leq 7.5^{\circ} \mathrm{C}\left(45.5^{\circ} \mathrm{F}\right)$ dew point

- Cabin Temperature $-21.1^{\circ} \mathrm{C}\left(70^{\circ} \mathrm{F}\right)$ except at $27^{\circ} \mathrm{C}\left(80.6^{\circ} \mathrm{F}\right)$ during sleep periods

- Pressure - 760 Torr (14.7 psia)

- SBAR cycle time - 6.5 minutes

- Bypass flow - actively controlled $-\mathrm{CO}_{2}$ pp set point at 4.8 Torr

It is expected that the vehicle will have a maximum capacity of $7 \mathrm{CM}$ and for ISS ferry missions the nominal duration would be less than 120 hours. To minimize the size of an SBAR system that could meet the higher crew capacity, an operational approach that utilized scheduled thermal regenerations was evaluated. Since the scheduled thermal regeneration for each SBAR unit would occur during alternate sleep periods, a successful test would be indicated by control of the $\mathrm{CO} 2$ and humidity levels when challenged with $3.5 \mathrm{CM}$ metabolic loads for 16 hours then with $7 \mathrm{CM}$ metabolic loads for 8 hours, followed by $3.5 \mathrm{CM}$ metabolic loads for another 16 hours.

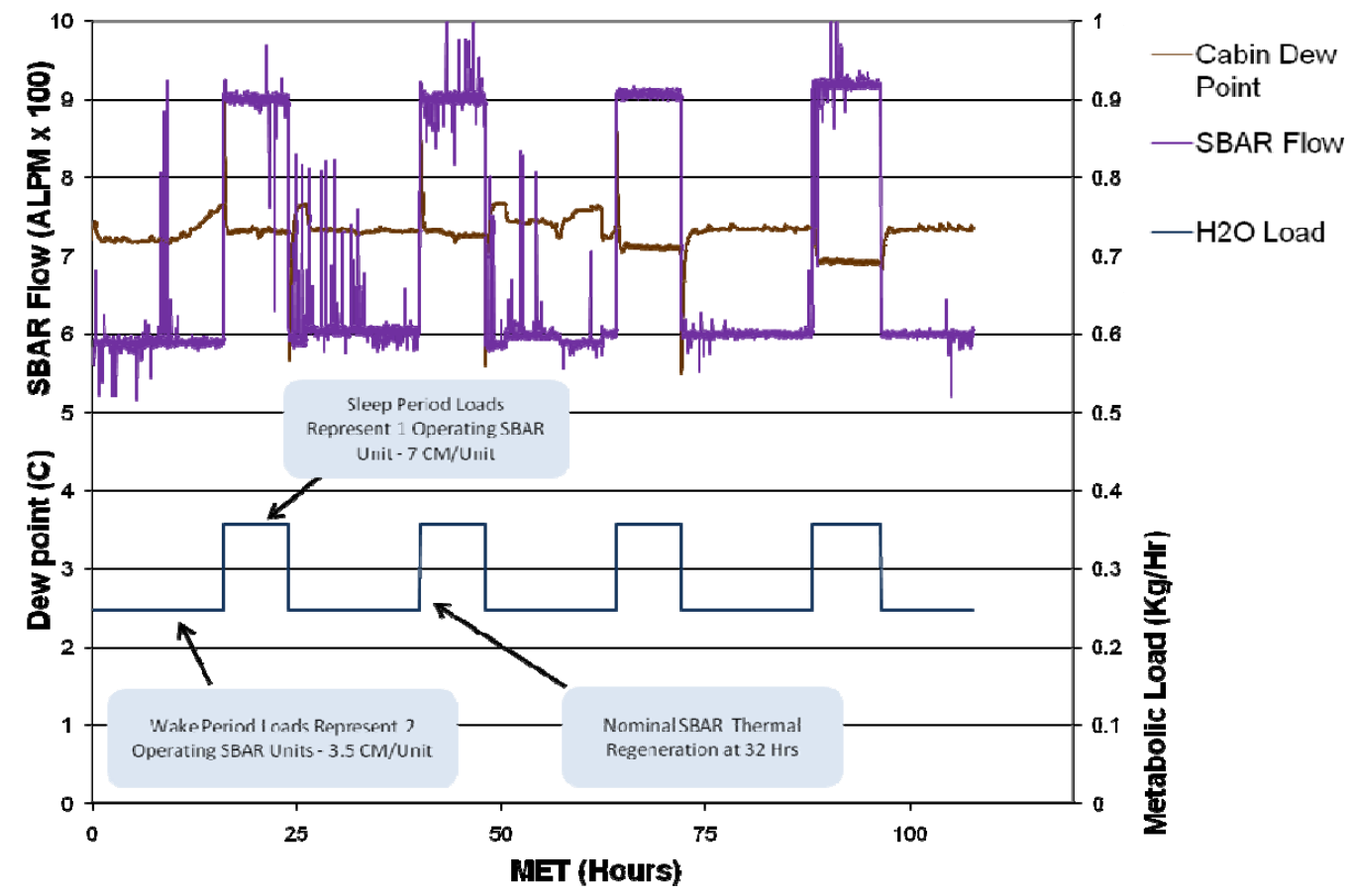

Figure $19 \mathrm{H}_{2} \mathrm{O}$ Control - 7CM Ferry w/ Alternate Thermal Regeneration

The cabin humidity levels and SBAR flow rates are shown in Figure 19. The high mass flow rates required for the test presented some challenges for the test facility which, for majority of the test, placed a higher adsorption pressure then the nominal 760 Torr expected for an ISS ferry mission vehicle. This represents a more challenging 
parameter for SBAR operation and was allowed to stay in place for majority of the mission simulation. Although successful control of humidity and $\mathrm{CO}_{2}$ levels beyond 40 hours MET would indicate the viability of the approach for unlimited duration missions, the simulation was allowed to continue with a non-regenerated unit to verify operational margins. At $\approx 88$ hours into the simulation the adsorption pressure was decreased to the nominal 760 Torr level and the subsequent higher volumetric flow rate decreased the cabin dew point.

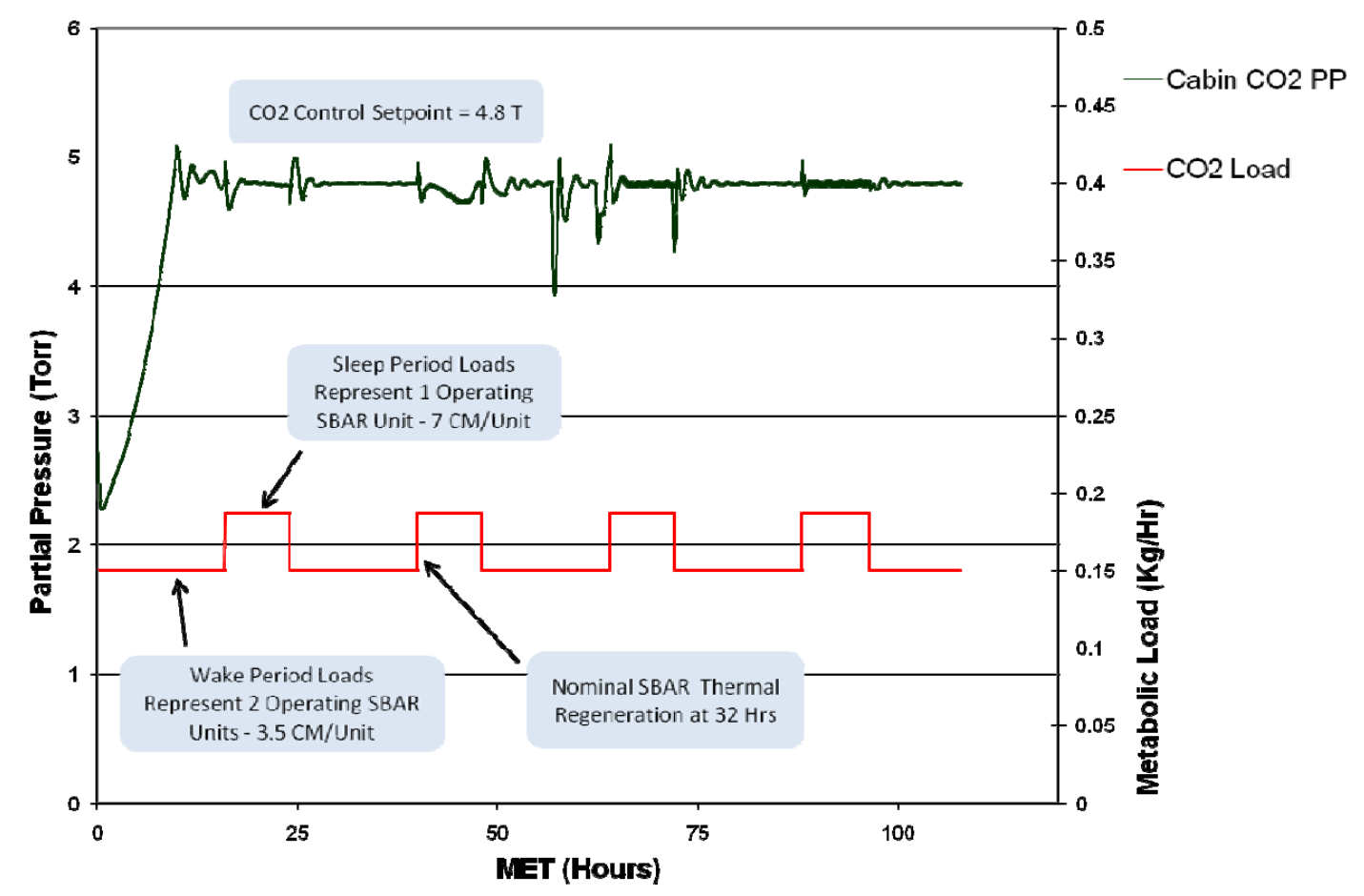

Figure $20 \mathrm{CO}_{2}$ Control - 7CM Ferry w/ Alternate Thermal Regeneration

The cabin $\mathrm{CO}_{2}$ partial pressure levels are shown in Figure 20. Levels were well controlled for the duration of the mission. There also appeared to be minimal impact when the adsorption pressure was lowered at $\approx 88$ hours MET. Previous testing has indicated that lower absorption pressures do tend to increase the $\mathrm{CO}_{2}$ removal performance over longer durations. The $\mathrm{CO}_{2}$ partial pressure levels were well within HSIR limits when the simulation was terminated at $\approx 108$ hours MET indicating that alternate thermal regeneration operation is a viable approach for addressing high metabolic load conditions for an unlimited mission duration.

\section{Post Test Inspections}

The underlying technology of beds packed with molecular sieve zeolites has been proven safe and effective in spacecraft life support applications ranging from Skylab to the ISS. Some systems, however, have encountered issues with dust generation and contamination and the subsequent restriction of air flow and damage to downstream components. Due to this, concerns have been expressed that the SBAR, which also uses packed beds of zeolite materials, might have similar issues. Like other fully open loop ARS technologies, the SBAR system is not intended for extended duration missions or long periods of operation without servicing.

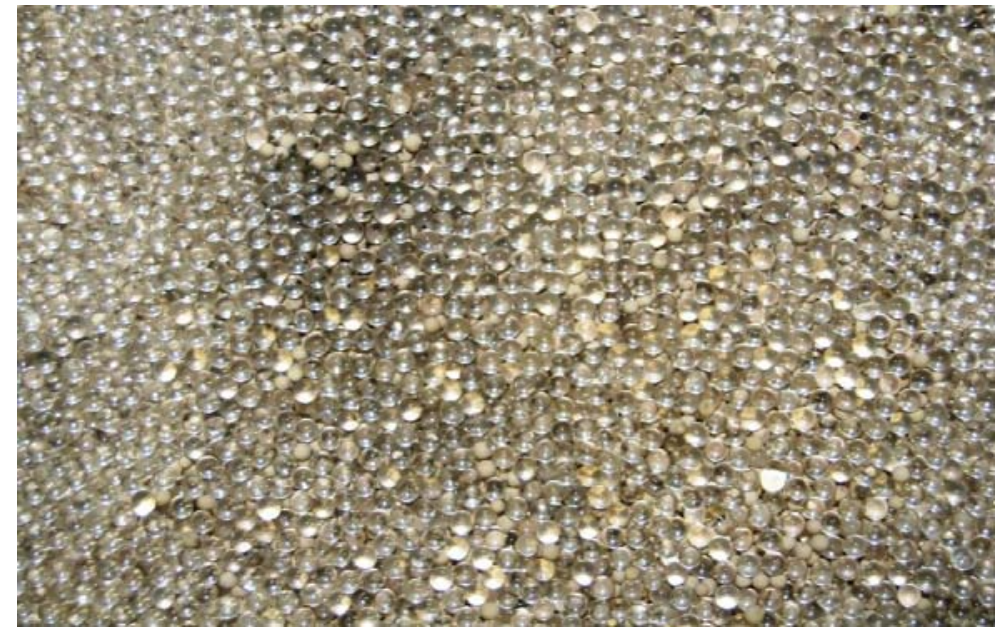

Figure 21 Minimal Dust Could be Found in Zeolite Material

American Institute of Aeronautics and Astronautics 
Nonetheless, dust generation and containment issues were considered during the design of the breadboard test articles. A post-test inspection of the test facility and SBAR Bed assemblies was performed to assess dust generation characteristics and the performance of the containment approach. The bed assemblies were disassembled and inspected after they each had been subjected to cyclic operation for $>1500$ hours.

The inspection results showed that there had been minimal impact on the bed assemblies. While the operational time was significantly longer than any projected mission scenario, no significant dust accumulations could be found in the zeolite material or against the $50 \mu \mathrm{m}$ containment screens.

Figure 21 shows a close-up view of the top 13X layer of material after removal of the baffle plate. A single layer of glass beads protects the zeolite beads from the metal screen but no loose dust could be seen above or below the beads indicating no restriction to flow had developed over the operational period. There was some settling of the zeolite material although the spring loaded containment systems maintained compression of the packed beads.

As can be seen in the photograph in Figure 22 , there was a small amount of fine dust observed in the gaps between the top baffle plate assembly, the bed canister walls, and the top cover on both bed assemblies. This dust was not found on the bottom (5A) end of the bed assemblies. There are differences in the flow environment between the top and the bottom of the bed assembly. During the adsorption half-cycle the process flow enters the top of the bed and exits through the bottom. When the SBAR transitions to the desorption half-cycle the vacuum is initially pulled from the top causing a short duration of high flow as the bed is evacuated. There is also a short duration of high flow into the bed from the top during the transition back to the adsorption half-cycle. It is probable that these pressure pulses account for the accumulation of fine dust particles in the trapped air gap at the top baffle plate assembly. The transitional flow rates at the bottom of the bed during the half-cycle change is significantly less, which may account for the fact that no dust accumulation was found in the bottom of the beds.

The plumbing and the downstream valve for

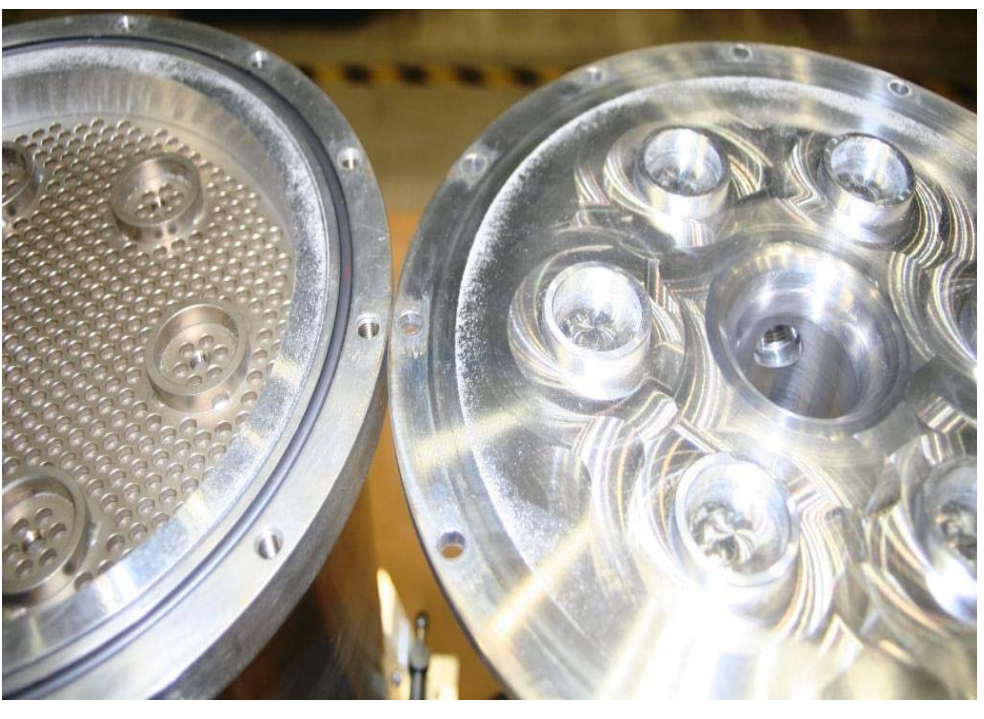

Figure 22 Top (13X) Cover and Baffle Plate Assy Showed a Small

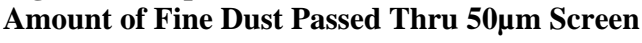

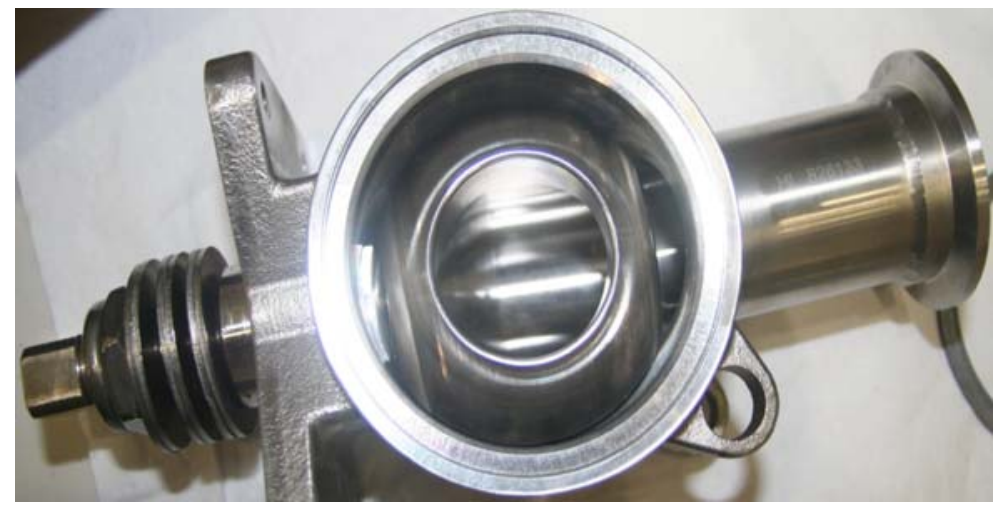

Figure 23 Disassembled Valves Appeared Shiny and Clean the SBAR system was also inspected. Figure 23 is a photograph of a typical valve after removal from the system. A fine powder residue adhering to the walls of the vacuum lines was observed but no accumulation of dust within the valve could be found. The sealing surfaces of the valve showed no signs of abrasion or excessive wear.

\section{Conclusions}

Tests and analyses have verified that an SBAR system is a viable and safe alternative for $\mathrm{H}_{2} \mathrm{O}$ and $\mathrm{CO}_{2}$ removal functions for vehicles that were defined in the Constellation Program. In addition, tests have shown that the technology is also suitable for vehicles currently under development for future spacecraft and missions. The SBAR 
system used for this evaluation, although development hardware, is of sufficient fidelity with respect to size and configuration that performance data from testing is directly applicable to potential spacecraft applications. The testing confirmed that $\mathrm{CO}_{2}$ and $\mathrm{H}_{2} \mathrm{O}$ removal requirements were met for nominal and off-nominal conditions for standard duration missions without thermal regeneration for a crew of 6. Larger crews and mission durations were also validated when operations include scheduled thermal regenerations.

The modification to the SBAR design to bypass a portion of the flow around the $\mathrm{CO}_{2}$ removing layer of the bed assembly was found to significantly extend the time before a thermal regeneration would be required. While adding some complexity to the design, the capability to actively control the bypassed flow allows the system to control the $\mathrm{CO}_{2}$ to a set point over a wide range of metabolic load conditions. Testing with the full 2-bed SBAR system verified the results of the testing with the single bed test article and showed that the air-save bed pressure equalization steps in the SBAR operation cycle had minimal effect on performance. Testing at conditions compatible with integration into a water-saving ARS showed that a single SBAR system could remove all metabolic $\mathrm{CO}_{2}$ produced by 6 crewmembers for the duration of a mission.

Although the testing conducted with the SBAR breadboard demonstrated acceptable performance for all currently envisioned short and mid-term crewed missions, areas for future development have been identified. The primary development effort required to bring the tested configuration closer to a flight-like design is the implementation of an optimized valve system which would decrease the system mass and the physical envelope, improve the flow path conductance, and incorporate features to assure that any generated dust would not impact reliability.

\section{References}

\footnotetext{
${ }^{1}$ Knox, J. C., Miller, L., \& Howard, D. Development and Testing of a Sorbent-Based Atmosphere Revitalization System for the Crew Exploration Vehicle 2007/2008, 2008-01-2082. SAE International, San Francisco, CA, 2008

${ }^{2}$ Miller, L. A., \& Knox, J. C. Development and Testing of a Sorbent-Based Atmosphere Revitalization System 2008/2009, 2009-01-2445. SAE International, Savannah, GA, 2009

${ }^{3}$ Lewis, John et. al., "Crew Exploration Vehicle Environmental Control and Life Support Development Status", 2007-013044 SAE International, Chicago, 2007

4 JSC-65527A, "Exploration Life Support Requirements Document," NASA Johnson Space Flight Center, Houston Texas, Revision A, June 2008

${ }^{5}$ CxP 70024 "Constellation Program Human-Systems Integration Requirements (HSIR)", NASA, Revision B, 3 March, 2008

${ }^{6}$ JSC-08934. Shuttle Operational Data Book, Volume 1, Rev. E. NASA Johnson Space Center, TX : Johnson Space Center, 1990.

${ }^{7}$ Howard, D. F., Perry, J. L., Knox, J. C., Roychoudhury, S., and Junaedi, C., "Performance Evaluation of Engineered Structured Sorbents for Atmosphere Revitalization Systems On Board Crewed Space Vehicles and Habitats". To be Presented, AIAA, $41^{\text {st }}$ International Conference on Environmental Systems, July 2011
} 